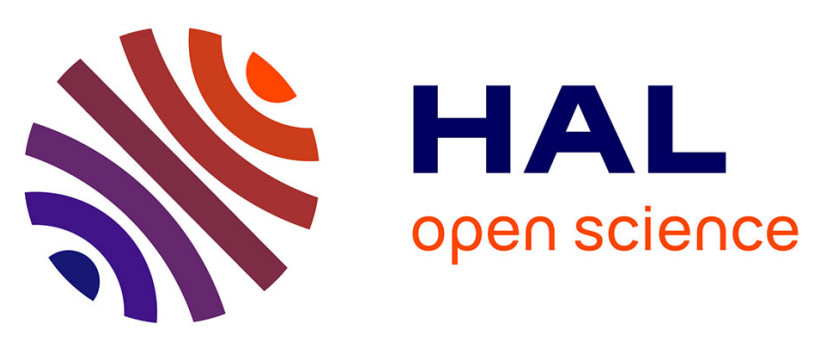

\title{
Evaluation of the AROME model's ability to represent ice crystal icing using in situ observations from the HAIC 2015 field campaign
}

\author{
Jean Wurtz, Dominique Bouniol, Benoît Vié, Christine Lac
}

\section{To cite this version:}

Jean Wurtz, Dominique Bouniol, Benoît Vié, Christine Lac. Evaluation of the AROME model's ability to represent ice crystal icing using in situ observations from the HAIC 2015 field campaign. Quarterly Journal of the Royal Meteorological Society, 2021, 147 (738), pp.2796-2817. 10.1002/qj.4100 . hal03357442

\author{
HAL Id: hal-03357442 \\ https://hal.science/hal-03357442
}

Submitted on 28 Sep 2021

HAL is a multi-disciplinary open access archive for the deposit and dissemination of scientific research documents, whether they are published or not. The documents may come from teaching and research institutions in France or abroad, or from public or private research centers.
L'archive ouverte pluridisciplinaire HAL, est destinée au dépôt et à la diffusion de documents scientifiques de niveau recherche, publiés ou non, émanant des établissements d'enseignement et de recherche français ou étrangers, des laboratoires publics ou privés. 


\section{Quarterly Journal of the Royal Meteorological Society \\ A journal of the atmospheric sciences and physical oceanography}

\section{Evaluation of the AROME model's ability to represent ice crystal icing using in situ observations from the HAIC 2015 field campaign}

\begin{tabular}{|c|c|}
\hline Journal: & QJRMS \\
\hline Manuscript ID & QJ-20-0309.R2 \\
\hline Wiley - Manuscript type: & Research Article \\
\hline $\begin{array}{r}\text { Date Submitted by the } \\
\text { Author: }\end{array}$ & 07-May-2021 \\
\hline Complete List of Authors: & $\begin{array}{l}\text { Wurtz, Jean; Météo-France CNRM, 42, avenue Gaspard Coriolis } 31057 \\
\text { Bouniol, Dominique; Météo-France/CNRS, CNRM/GAME } \\
\text { Vié, Benoît; METEO-FRANCE, CNRM/GMME/PHY-NH } \\
\text { Lac, Christine; METEO-FRANCE, CNRM/GMME/PHYNH }\end{array}$ \\
\hline Keywords: & $\begin{array}{l}\text { Observational data analysis }<1 \text {. Tools and methods, Regional and } \\
\text { mesoscale modelling }<1 \text {. Tools and methods, Ice/icing }<3 \text {. Physical } \\
\text { phenomenon, Convection }<3 \text {. Physical phenomenon, Microphysics }<3 \text {. } \\
\text { Physical phenomenon, Atmosphere }<4 \text {. Geophysical sphere }\end{array}$ \\
\hline Country Keywords: & France \\
\hline
\end{tabular}




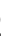

1 Evaluation of the AROME model's ability to

2 represent ice crystal icing using in situ observations

3 from the HAIC 2015 field campaign

4

Jean Wurtz, Dominique Bouniol, Benoît Vié, Christine Lac

6 CNRM, Université de Toulouse, Météo-France, CNRS, Toulouse, France

7 Corresponding author: Jean Wurtz, CNRM - Météo-France, 42 avenue Gaspard

8 Coriolis, 31057 Toulouse, France. email:jean.wurtz@meteo.fr

9 Keywords: Observational data analysis, Mesoscale modelling, ice/icing, convection,

10 microphysics, atmosphere

11 Funding: None

12

13

14 


\section{$\underline{\text { Abstract: }}$}

2 Since pilots generally avoid intense convective areas, Ice Crystals Icing (ICI) is an

3 aeronautical weather incident that mainly occur in the anvil of tropical deep convective

4 clouds. Samples of favorable conditions for the occurrence of ICI and data from the High

5 Altitude Ice Crystals (HAIC) 2015 field campaign in French Guiana are investigated and

6 compared to simulations of the French operational mesoscale forecast system AROME.

7 To this end, a contextualization of convective systems into convective, stratiform and

8 cirriform regions is employed for both observations and AROME. General features of the

9 microphysics of deep tropical convective systems are identified. The concentration

10 number of crystals larger than $125 \mu \mathrm{m}$ and total water content (TWC) are strongly

11 correlated at each temperature level and both decrease the further they are from

12 convective cores. AROME is able to reproduce the general behavior of the observed

13 microphysics, especially TWC, but seems unable to simulate extreme ICI events.

14 Reasons are sought in the assumptions performed in the microphysical scheme ICE3 and

15 guidelines are proposed to enhance its skills in the context of ICI. In particular, the

16 representation of the snow particle size distribution is adjusted across observations using

17 a generalized gamma shape. This shape is found to outperform the usual Marshall-Palmer

18 and gamma shapes. Additionally, a temperature and snow content dependency of

19 generalized gamma parameters has been found. These changes are found to significantly

20 improve the snow concentration diagnostic of ICE3 and these modifications open room

21 for improvements in the ICE3 scheme. 


\section{1) Introduction}

2 As early as 1963, Simpson (1963) reported icing on aircraft at temperatures as low as -

$360^{\circ} \mathrm{C}$. This was attributed to the presence of supercooled liquid water in the highest levels

4 of the convective updrafts. Such a hypothesis was refuted by Schaefer (1962), who

5 claimed that supercooled cloud droplets cannot be found at temperatures lower than -

$6 \quad 40^{\circ}$ C. Further studies (e.g. Heymsfield \& Miloshevich, 1993; DeMott \& Rogers, 1990)

7 found no supercooled cloud droplets either at temperatures colder than $-38^{\circ} \mathrm{C}$.

8 Later, during the '90s, multiple flight incidents due to the accretion of ice on the engines

9 or on the aircraft instruments occurred at relatively high altitudes in low air temperatures

10 (between $-27^{\circ} \mathrm{C}$ and $-33^{\circ} \mathrm{C}$ ) and mainly while aircraft were cruising in regions of the

11 convective system considered as safe (Lawson et al. 1998). The presence of supercooled

12 cloud droplets was not expected at such altitudes (Bernstein et al., 2009). Inquiries based

13 on pilots' reports helped to comprehend the cloud microphysical characteristics and the

14 environmental weather conditions of these events (Mason et al., 2006; Grzych \& Mason,

15 2010; Mason \& Grzych, 2011; Bravin \& Strapp 2019). They concluded that high ice

16 water contents (IWC) of relatively small ice particles in high concentrations are

17 responsible for these incidents. Such ice particles, when hitting the aircraft engines or its

18 instrumentation, can melt due to the heat released by friction or by the engines, and

19 freeze afterwards, leading to ice accretion through time (Mason et al. 2006). This kind of

20 icing event is referred to as ice crystals icing (ICI). During an ICI event, pilots encounter

21 low to moderate turbulence with neither supercooled liquid water nor graupel, but high 
1 and sustained IWC, in spite of no warning signal on the onboard radar. It was specifically

2 highlighted in these studies that ICI seems to be more frequent in the anvil of oceanic

3 tropical mesoscale convective systems (MCS) (Houze, 2018) in their mature to

4 dissipating stage (Houze, 1982).

5 To avoid severe weather, including convective towers, aircraft are equipped with an

6 onboard X-band $(\sim 10 \mathrm{GHz})$ radar. Green echos $(\mathrm{Z}<30 \mathrm{dBz})$ are recognized as safe.

7 Orange or red echos $(\mathrm{Z}>30 \mathrm{dBz})$ are considered as hazardous and correspond to clouds

8 containing high quantities of liquid water or large rimed particles including graupel and

9 hail. Proctor et al. (2017) showed that, even in cases of high IWC, the reflectivity,

10 without rimed particles, remains below $30 \mathrm{dBZ}$. As a consequence, while onboard radar

11 enables the avoidance of high IWC found in MCS convective regions (due to its

12 sensitivity to large rimed particles) allowing pilots to deroute, it is unable to detect the

13 presence of the high IWC near these cores, which could lead to ICI.

14 Houze et al. (1980) separate MCS into three distinct dynamical regions referenced as the

15 convective, stratiform (precipitating anvil) and cirriform (nonprecipitating anvil) regions.

16 Each region is associated with different microphysics (Barnes \& Houze, 2014) which is

17 worth documenting, especially in the context of ICI.

18 The sharp ascending region of MCSs is known as the convective region. As a result of

19 the condensation in the ascending air, cloud droplets and ice crystals form. Interactions

20 between hydrometeors result in the formation of snow, graupel or hail (Heymsfield,

21 1978). Heavy precipitation is usually found within or near convective cores (Zipser, 
1 1977). When reaching a negative buoyancy barrier (which can be the tropopause),

2 hydrometeors are transported horizontally forming the anvil cloud. Covering broad areas

3 with sustained rain underneath (Steiner et al. 1995; Houze 1997), the precipitating anvil

4 is known as the stratiform region. Here, vertical motions persist as moderate mesoscale

5 ascents in the ice phase region of the cloud and mesoscale descents in the liquid phase of

6 the cloud (Zipser 1977; Gamache \& Houze, 1982) are respectively attributed to latent

7 heating and evaporation cooling (Cifelli \& Rutledge 1998; Brown, 1979). This

8 circulation favors the formation and the sedimentation of aggregates and large ice

9 particles can be found at the base of ice stratiform clouds, while smaller crystals are

10 generally found aloft (Barnes \& Houze, 2014). ICI is generally encountered within the

11 uppermost region of these anvils. Further away from the convective region, the

12 nonprecipitating anvil is called the cirriform region. This thinner region of the MCS is

13 composed of ice crystals and small aggregates (Protat et al. 2011). It is maintained aloft

14 by a radiative instability leading to weak but large extended ascents. (Gasparini et al.

15 2019; Wall et al. 2020). Within these clouds, ice crystals formed in situ by heterogeneous

16 nucleation such as bullet rosettes can be found (Lawson et al. 2010; Protat et al. 2011).

17 Although the large-scale organization of MCSs is well understood, detecting, forecasting

18 and understanding the processes leading to ICI conditions, remains a challenge. As a

19 consequence, the High Altitude Ice Crystals (HAIC) European project together with the

20 US High Ice Water Content project (HIWC) was conducted and resulted in three airborne

21 field campaigns (Darwin in 2014, French Guiana in 2015 and La Reunion/Darwin in

22 2016) coordinated with advances in satellite-based detection (DeLaat et al. 2017; Yost et 
1 al. 2018; Haggerty et al. 2019) of ICI being developed, as well as a now-casting product

2 based on ground based radar, geostationary satellites, and numerical weather prediction

3 (NWP) (Haggerty et al., 2020).

4 During these campaigns, it has been found that secondary ice production (Korolev et al.

5 2020), and deposition (Leroy et al. 2017) favor the formation of a mode of a few

6 hundreds of micrometers in the particle size distribution (PSD), responsible for the high

7 ice water content.

8 Numerical studies were also conducted: Ackerman et al. (2015), by performing

9 sensitivity tests using a bin microphysical model not only pointed out the role of several

10 microphysical processes such as secondary ice production and deposition, but also

11 highlighted environmental conditions such as the updraft strength and the number of

12 cloud condensation nuclei $(\mathrm{CCN})$. Cloud resolving simulations were also part of HAIC

13 and HIWC: Huang et al. (2020) or Franklin et al. (2016) using several microphysical

14 schemes (including two moment schemes and evolutions of their microphysical schemes)

15 conclude the need to better handle cloud water and graupel to successfully simulate X-

16 band reflectivities. Turbulence was also singled out as an important process which may

17 play a key role in the simulation of vertical velocities and the modification of cloud

18 microphysical composition and processes. Proctor et al. (2017) using large eddy

19 simulations were successful in simulating broad areas of high IWC with low X-band

20 reflectivities in spite of a simple single moment bulk microphysical scheme.

21 Following on from these previous studies, the present paper aims to identify the 
1 microphysical characteristics favorable to ICI in MCSs and to assess the ICI prediction

2 skills of the French operational mesoscale model AROME (Application of Research to

3 Operations at Mesoscales). In order to do this, MCSs sampled during the HAIC 2015

4 field campaign and the corresponding simulated MCS in AROME are analyzed

5 separately in convective, stratiform and cirriform regions.

6 Section 2 describes the model and provides an overview of the data used in the present

7 study. The comparison method based on the identification of the different dynamical

8 regions of MCSs for both in situ data (using independent microwave and infrared satellite

9 images) and the AROME NWP model is presented in section 3. The in situ data is then

10 analyzed in light of this dynamical context in section 4 and compared in section 5 to

11 AROME outputs. In section 6 investigations of the observed PSD are carried out to

12 propose improvements for AROME.

\section{2) Data}

\section{2.1) In situ observations of the 2015 HAIC field campaign}

15 This study makes use of data collected during the second HAIC field campaign which

16 took place in May 2015 in French Guiana by the Falcon-20 operated by the French

17 scientific national research center (CNRS - Centre National de la Recherche Scientifique:

18 National centre of scientific research) SAFIRE (Service des Avions Français

19 Instrumentés pour la Recherche en Environnement, the French facility for airborne 
1 research).

2 This aircraft performed 17 flights (including one test flight), which lasted for

3 approximately 3 hours. For safety reasons, flights were scheduled during day-light time.

4 The month of May corresponds to the second maximum of the rainy season over French

5 Guiana after a more commonly drier spell in March. At this time of year, the inter-

6 tropical convergence zone moves northward from the amazonian forest bringing warm

7 and moist air favorable to deep convection (Boyé et al. 1979). The Falcon-20 favored the

8 sampling of mature to decaying oceanic MCS cloud anvils where total water content

9 (TWC) is higher than $0.1 \mathrm{~g} / \mathrm{m}^{3}$ at usual commercial flight levels corresponding to the

10 temperature levels: $-10^{\circ} \mathrm{C},-30^{\circ} \mathrm{C}$ and $-45^{\circ} \mathrm{C}$. More precisely, these three levels were

11 sampled in the range $-8^{\circ} \mathrm{C}$ to $-15^{\circ} \mathrm{C} ;-22^{\circ} \mathrm{C}$ to $-34^{\circ} \mathrm{C}$ and $-37^{\circ} \mathrm{C}$ to $-45^{\circ} \mathrm{C}$ respectively.

12 Intense convective towers associated with lightning, high turbulence and $\mathrm{X}$ band on-

13 board radar reflectivities higher than $30 \mathrm{dBz}$ were avoided as much as possible (Strapp et

14 al. 2016; Coutris 2019).

15 Among others, the Falcon-20 was equipped with advanced instruments enabling a fine

16 sampling of the cloud microphysics:

17 - The RASTA (RAdar SysTem Airborne) (Protat et al. 2009, Delanoë et al. 2007)

$1895 \mathrm{GHz}$ Doppler radar.

19 - A cloud droplet spectrometer probe (CDP-2) (Lance et al. 2010) measuring the PSD

20 concentration of liquid particles and very small ice particles in the range of $2-50 \mu \mathrm{m}$. 
1 Supercooled liquid water was rarely sampled especially at $-30^{\circ} \mathrm{C}$ and $-45^{\circ} \mathrm{C}$ levels

2 (Schwarzenboeck et al. 2018), consistent with Stith et al. (2004), and pilots' reports.

3 CDP-2 ice particle measurements can be very noisy in the case of high concentration and

4 are therefore hard to deal with statistically so are not used in this study.

5 - The Iso-Kinetic Probe (IKP-2) sampling the cloud TWC at the flight level every second

6 with a confidence level above $0.1 \mathrm{~g} / \mathrm{m}^{3}$. It was specifically designed to sample high TWC

7 at high speed. It can measure up to at least $10 \mathrm{~g} / \mathrm{m}^{3}$ at a $200 \mathrm{~m} / \mathrm{s}$ air speed with a $20 \%$

8 accuracy as an objective (Davison et al. 2008). Uncertainties of this instrument are fully

9 reviewed in Davison et al. (2016).

10 - The 2D Stereo probe (2DS) (Lawson et al. 2006) and Precipitation Imaging Probe (PIP)

11 (Field et al. 2006) are crystal imagers. 2DS samples crystals range from 10 to $1280 \mu \mathrm{m}$

12 and PIP from 100 to $6400 \mu \mathrm{m}$. Their combination allows the derivation of a PSD between

1310 and $12850 \mu \mathrm{m}$ every 5 seconds with a resolution of $10 \mu \mathrm{m}$ and a total propagated

14 uncertainty ranging from 10 to $100 \%$ (Baumgardner et al. 2017). The 2DS is employed

15 between $10 \mu \mathrm{m}$ to $800 \mu \mathrm{m}$ while the PIP is employed between $1200 \mu \mathrm{m}$ to $12850 \mu \mathrm{m}$.

16 Between 800 and $1200 \mu \mathrm{m}$ a linear interpolation between the two measured spectra is

17 made for self consistency (Leroy et al. 2016). Particles larger than $6400 \mu \mathrm{m}$ may be

18 partly sampled by the PIP and the size correction of Korolev \& Sussman (2000) enables

19 the extension of the PSD up to $12850 \mu \mathrm{m}$. Although anti-shattering tips were developed

20 on probes (Korolev et al., 2013) and data post-processing was improved to detect

21 shattering (Field et al. 2006; Korolev \& Field 2015), the small crystal concentrations 
1 have to be carefully considered as shattering of ice crystals on the probe may artificially

2 increase the concentration in the smallest bins.

3 Many diameter definitions may be considered in order to represent the size of three

4 dimensional particles sampled by two dimensional images. Wu and McFarquhar (2016)

5 showed that different definitions can lead to errors of up to a factor of 6 in the

6 concentration estimates for crystals larger than $2000 \mu \mathrm{m}$ or smaller than $200 \mu \mathrm{m}$. In this

7 study, $D_{\max }$, defined as the maximum possible diameter passing through the barycentre of

8 the two dimension crystal picture (see Figure 1 of Leroy et al. (2016)) is chosen. The

9 AROME model uses Locatelli \& Hobbs (1974) relationships using $D_{\max }$. Hence,

10 choosing $\mathrm{D}_{\max }$ will facilitate the comparison between HAIC observations and AROME.

11 Because of shattering, ice crystals smaller than $125 \mu \mathrm{m}$ are excluded and the total

12 concentration number $(\mathrm{N})$ is defined by integrating the PSD from $125 \mu \mathrm{m}$ to $12850 \mu \mathrm{m}$.

13 Note that crystals smaller than $125 \mu \mathrm{m}$ do not account for much of the TWC. In our data

14 set, the mass of crystals below this threshold generally represents less than $3 \%$ of the

15 TWC. Setting this lower integration boundary to $125 \mu \mathrm{m}$ also separates the two modes

16 commonly observed in ice PSDs (Ackerman 2015; Leroy et al. 2017; Fontaine et al.

17 2020; Field \& Heymsfield 2003; Wu \& McFarquhar 2016 among others).

18 Using IKP-2 and a 3D ice particle model, a mass-diameter relationship has been derived

19 from each observed PSD by adjusting a power law (Equation 1) (Leroy et al. 2016;

20 Fontaine et al. 2014): 
2 Hence, a pair of parameters $\left(a^{*}, b^{*}\right)$ representative of the best mass-diameter

3 relationships are available for each observed PSD.

4 As a result, the mass size distribution (MSD) can be computed for each PSD n(D):

${ }_{5} M S D(D)=n(D) m(D)$

6 This mass distribution is commonly characterized using the median mass diameter

7 (MMD) which is the median diameter of the ice mass distribution, and here computed as

8 in Mitchell (1991).

\section{2.2) The French operational mesoscale model AROME}

10 AROME simulations are performed starting from 00UTC in the domain of Figure 1

11 between May 09, 2015 and May 29, 2015 corresponding to the first and last days of

12 operation of the Falcon-20 during the HAIC field campaign of 2015. The AROME model

13 (Seity et al., 2011; Brousseau et al. 2016) is a non-hydrostatic limited area model used by

14 the French operational meteorological service for up to 48-h forecasts. It shares its

15 package of physical parameterizations with the Mesoscale Non-Hydrostatic (Meso-NH)

16 French research model (Lac et al., 2018), and its dynamical core with Aladin-NH

17 (Bubnová et al. 1995). AROME functions not only in France and continental Europe in

18 its operations but also overseas (Faure et al., 2020). As a result, a specific AROME 
1 domain of approximately $1200 \mathrm{~km}$ length and $900 \mathrm{~km}$ width is implemented in French

2 Guiana (Figure 1). The model is run with its operational setups: 60 seconds time step and

3 a $2.5 \mathrm{~km}$ horizontal resolution. The vertical dimension extends from $\sim 5 \mathrm{~m}$ up to $\sim 34 \mathrm{~km}$

4 using 90 vertical levels, most of them located near the surface meaning a vertical

5 resolution decrease overhead from $10 \mathrm{~m}$ near the surface to $100 \mathrm{~m}$ at the top of the mixing

6 layer and roughly $400 \mathrm{~m}$ at $10 \mathrm{~km}$ high.

7 Because of a grid change, before the AROME model was operational over Guyana, the

8 initial and forcing conditions usually provided by the European Centre for Medium-

9 Range Weather Forecasts Integrated Forecasting System (ECMWF-IFS) have been

10 replaced by the ones provided by ARPEGE (Action de Recherche Petite Echelle Grande

11 Echelle, Courtier et al., 1991), the French operational global forecast system. This

12 alteration should not impact the results presented here.

13 The incremental analysis update algorithm from Bloom et al. (1996) is used to reduce

14 model spin-up. An initial AROME run beginning 6 hours before the 00UTC network is

15 used to initialize water related variables at the 00UTC network. Nevertheless, spin-up can

16 still influence the results of cloud microphysics for the very first hours of forecast. As a

17 result, the first three hours of simulations are not considered.

18 AROME implements fine descriptions of atmospheric and surface physics. It uses a

19 convection-permitting $2.5 \mathrm{~km}$ grid spacing and shallow convection is parameterized

20 following Pergaud et al. (2009). A radiation scheme based on Mlawer et al. (1997),

21 Fouquart and Bonnel (1980) and Morcrette (1991) is used to describe atmospheric 
1 radiative transfer. The atmospheric turbulence is described by a one dimension scheme,

2 so without any horizontal mixing, based on a prognostic equation of Turbulent Kinetic

3 Energy (Cuxart et al., 2000). The simulation domain (Figure 1) includes a large fraction

4 of oceanic surface $(\sim 70 \%)$. The state of the ocean surface largely influences not only

5 cloud organization and the convection life cycle of low clouds (Chung et al., 2012; Klein

6 \& Hartmann, 1993), but also that of deep convective clouds (Costa et al., 2001). The

7 coupling with oceanic surface is performed by a 1D column model (CMO, Lebeaupin,

8 2007) initialized by the MERCATOR PSY4 ocean model at a resolution of $1 / 12$ of a

9 degree (Lellouche et al., 2018). Interactions between continental surfaces and atmosphere

10 are described by the surface scheme SURface Externalisée (SURFEX, Masson et al., $112013)$.

12 The operational model AROME implements the ICE3 single moment bulk microphysical 13 scheme (Pinty and Jabouille, 1998). In addition to the water vapor, three ice species 14 (pristine ice, snow and graupel) and two liquid water species (cloud droplets and rain 15 drops) are used in order to represent the cloud microphysics. For each hydrometeor type 16 the only prognostic variable is the mass mixing ratio. The ICE3 has been further 17 improved by Riette (2020) with a reduction to the time-step dependency. The warm phase 18 is described by the Kessler (1969) scheme. Each hydrometeor is described using two 19 power-laws taken from Locatelli \& Hobbs (1974) and Heymsfield (1972) for ice 20 hydrometeors. The mass-diameter and terminal fall velocity - diameter relationships are 21 expressed as power laws (see Equation 1) using for each ice species a and c as prefactors 22 and $\mathrm{b}$ and $\mathrm{d}$ as exponents. The respective values are given in Table I. 
1 A generalized gamma distribution is used to represent the PSD of each hydrometeor:

$2 n(D)=N_{i}=\frac{a}{\Gamma(\nu)} \lambda^{a \nu} D^{a \nu-1} \exp \left(-(\lambda D)^{a}\right)$

3 Here, $\mathrm{N}_{\mathrm{t}}$ is the total number concentration of the described species and $\alpha, v$ are called

4 shape parameters (see Table I) for the different ice species. When $\alpha=1$ only two free

5 parameters remain and the PSD is named gamma in the following. If in addition $v$ is set

6 to 1 the PSD is named Marshall-Palmer (MP) (Marshall \& Palmer, 1948).

7 The $\lambda$ parameter is physically linked to the proportion of small versus large

8 hydrometeors: the higher the $\lambda$, the higher proportion of small hydrometeors (this feature

9 of $\lambda$ can be deduced from Equation 11). Cloud liquid water PSD is set differently based

10 on the surface type (oceanic or continental) underneath the cloud in order to indirectly

11 take into account the population of cloud condensation nuclei (Albrecht, 1989; Hudson \&

12 Yum, 2001).

13 For a given hydrometeor type, the total number concentration $\mathrm{N}_{\mathrm{t}}\left(\mathrm{m}^{-3}\right)$ is linked to the 14 mass content $\mathrm{r}\left(\mathrm{kg} / \mathrm{m}^{3}\right)$ through Equation 4:

$15 N_{t}=\frac{r \lambda^{b}}{a G(\alpha, \nu, b)}$

16 with:

$$
G(a, \nu, b)=\frac{\Gamma\left(\nu+\frac{b}{a}\right)}{\Gamma(\nu)}
$$

17 As ICE3 is a single moment scheme a closure assumption on $\mathrm{N}_{\mathrm{t}}$ or on $\lambda$ is needed to 18 completely describe the PSD. Using a MP law, Passarelli (1978) proposed to link N to $\lambda$ 
1 through a power law for snow, graupel and rain such as:

$2 N_{t}=C X^{2}$

3 Different values of $\mathrm{C}$ and $\mathrm{x}$ can be found in the literature for snow and graupel. Caniaux

4 (1993) tested multiple values of C and x. Among them, the values given in Table I are

5 used in the operational version of AROME.

6 Using Equation 6 in Equation 4:

$\lambda=\left(\frac{a C G(a, \nu, b)}{r}\right)^{\frac{1}{b-a}}$

8 Then, for precipitating ice species, the whole PSD can be deduced from the only

9 prognostic variable $\mathrm{r}$.

10 Cloud droplet concentration is a function of land surface and takes the constant value of

$113 \times 10^{8}$ and $1 \times 10^{8} \mathrm{~m}^{-3}$ over land and sea areas, respectively. For pristine ice, the

12 computation of $\mathrm{N}_{\mathrm{t}}$ is based on the supersaturation over ice (Meyers et al. 1992). The auto-

13 conversion of pristine ice to snow is allowed when it reaches a mass content threshold

14 dependent on the air temperature (Ryan, 2000; Chaboureau and Pinty, 2006).

15 TWC $\left(\mathrm{g} / \mathrm{m}^{3}\right)$ in AROME is defined as the sum of each condensed species mass content 16 per volume unit.

\section{3) Contextualization and comparison method}


1 Comparing in situ data to numerical simulations is tricky, especially in the case of deep

2 convection. A point to point comparison cannot be performed as location errors are

3 frequent in numerical simulations and because punctual observations have to be averaged

4 to a comparable spatial and temporal model grid point scale. To overcome this issue, the

5 three different dynamical regions of MCS, as described in the introduction are identified

6 for both the in situ observations and AROME outputs. The different microphysical

7 parameters of both observations and model outputs can then be compared individually in 8 each region.

\section{3.1) Observations}

10 Spaceborne observations are well suited for identifying the various MCS regions since

11 they offer a 2D mapping of convective systems and are independent of the in situ

12 observations. Hence this method can also be used without the presence of airborne

13 observations. The French Guiana region was in 2015 continuously sampled by the

14 geostationary satellite GOES13 and regularly by the microwave radiometers of the

15 Global Precipitation Measurement (GPM) constellation.

16 The GPM constellation includes nine microwave radiometers implementing a channel

17 close to $90 \mathrm{GHz}$ where Polarization-Corrected Temperature (PCT) (Spencer et al. 1989)

18 can be computed. In 2015, the average revisit time was around 1.5 hours on French

19 Guiana and the resolution of radiometers is approximately $4.4 \times 7.3 \mathrm{~km}$ (Hou et al. 2014).

20 PCTs at $90 \mathrm{GHz}$ are commonly used to identify the cloud convective and stratiform areas 
1 within tropical deep convection. The $90 \mathrm{GHz}$ channel is sensitive to the hydrometeor

2 scattering which is expected to be more important in the convective regions because of

3 strong updrafts forming diffusive ice such as graupel. Less diffusive ice, such as snow, is

4 expected to be found in the stratiform regions. Following Mohr and Zipser (1996), 250K

5 and $225 \mathrm{~K}$ thresholds are used to identify the stratiform and convective areas of the MCS

6 (Figure 2a). The 90Ghz PCT can be linked to surface precipitation rates (Adler et al.,

7 1990; Spencer et al, 1989). with the $250 \mathrm{~K}$ and $225 \mathrm{~K}$ levels corresponding to precipitation

8 rates higher than $3 \mathrm{~mm} / \mathrm{h}$ and $12 \mathrm{~mm} / \mathrm{h}$, respectively (Mohr and Zipser, 1996).

9 Infrared brightness temperatures from GOES13 are used to delimit the cirriform envelope

10 of the MCS. As in previous studies (Roca et al. 2017; Duvel 1989; Bouniol et al. 2016)

11 the $235 \mathrm{~K}$ threshold is used in the present study. These data are available every 30 minutes 12 at a $4 \mathrm{~km}$ horizontal resolution.

13 The combination of PCT and infrared images reasonably defines the system dynamics in 14 two dimensions as viewed from space (Figure 2 (b)).

15 Among the 16 flights performed during the HAIC 2015 campaign, 8 flights have 16 simultaneous data acquisition by at least one satellite of the GPM constellation. For the 8 17 others, when possible, extrapolations were made thanks to PCT acquired just before or 18 after the flight time. Unfortunately some images were missing during the field campaign, 19 especially for flights of May 21, 2015 and May 25, 2015 which were excluded due to the 20 lack of both PCT and infrared images. 
1 Good consistency between the RASTA vertical velocity and reflectivity measurements

2 with the corresponding identified region of MCSs was observed, confirming the

3 suitability of the satellite separation method (see supplement S1 and S3).

4 Aircraft data were sorted based on the sampled MCS region and split into 120 second

5 segments. All the ascents and descents of the Falcon-20 were excluded in order to keep a

6 homogeneous temperature sampling. In the following, a segment is defined as a small

7 flight leg performed at a given altitude in a given region of the MCS (convective,

8 stratiform or cirriform). To enable an inter-comparison of these segments, a constant

9 segment length of 120 seconds is set. A sensitivity test (not shown) for this threshold has

10 been conducted by setting the segment length to 60 and 30 seconds without a change in

11 the results. In the case of ICI conditions, this period can be considered as sufficient for

12 ice accretion on the aircraft's engine.

13 Figure 2 shows an illustration of this contextualization process. The Falcon-20 was flying

14 in a deep coastal MCS at an altitude where air temperature was close to $-30^{\circ} \mathrm{C}$. Thanks to

15 the PCT (Figure 2a) the convective and stratiform regions of the MCS are identified

16 (dash-dotted and dashed contours). GOES-13 infrared images are used to identify the

17 cirriform cloud edges with the 235K threshold (solid contour in Figure 2b). The Falcon-

1820 sampled the cirriform, stratiform and convective regions (before 0955 UTC, from

190955 UTC to 1000 UTC and from 1000 UTC to 1007 UTC respectively). A complete

20 summary of the data set after the segmentation process is given in Table II. In general the

21 sampled MCSs are oceanic and $82 \%$ of segments are found in anvil clouds. 


\section{3.2) AROME}

2 The same kind of contextualization can in theory be applied from the radiative transfer

3 for television and the infrared observation satellite operational vertical sounder (RTTOV)

4 radiative transfer model (Saunders et al., 2018) and used on AROME's outputs, enabling

5 the simulation of spaceborne sensors. RTTOV implements additional microphysical

6 assumptions that may not be completely in agreement with the ICE3 assumptions

7 however and differ among the infrared and microwave domains. Since the purpose of the

8 present study is an in depth analysis of in situ data and the evaluation of AROME,

9 avoiding additional assumptions on the microphysics is preferable. The simulated PCTs

10 (see supplement S2) are found to be consistent however with the identification method

11 using model variables (see further below), the choice has rather been to keep criteria

12 closer to AROME physics in order to identify convective, stratiform and cirriform

13 regions within the model simulations. The cirriform MCS envelope is defined by an ice

14 water path (IWP) larger than $0.5 \mathrm{~kg} / \mathrm{m}^{2}$. This criterion is used as a necessary condition for

15 a column to belong to a MCS and ensures a sufficient glaciated development of the cloud

16 excluding cumulus clouds. Several thresholds were tested from $0,01 \mathrm{~kg} / \mathrm{m}^{2}$ to $3 \mathrm{~kg} / \mathrm{m}^{2}$. A

17 too-low IWP criterion implies the detection of thin cirrus whereas a too-high threshold

18 may be too restrictive.

19 Many different methods have been proposed in order to identify MCS convective and

20 stratiform regions, most of them based on precipitation rates, vertical velocities and liquid

21 water content or IWC. Lang et al. (2003) performed a comparison of these different 
1 methods. The variability of the criteria and thresholds is large, but the main features of

2 the convective and stratiform regions are shared. In our study, in addition to an IWP

3 criterion and following $\mathrm{Xu}$ (1995) and Lang et al. (2003), a column is considered as

4 convective if the maximum vertical velocity is larger than $2.5 \mathrm{~m} / \mathrm{s}$ or if surface

5 precipitation rain rate is larger than $15 \mathrm{~mm} / \mathrm{h}$. The vertical velocity threshold allows the

6 identification of the strong ascents in the convective towers. Stratiform regions are

7 identified as non convective columns and with a surface rain rate larger than $1 \mathrm{~mm} / \mathrm{h}$.

8 Note that the chosen rain rate thresholds are close to those expected under the stratiform

9 and convective classification by PCT (cf. Section 3.1).

10 Figure 3 shows the convective system shown in Figure 2 simulated by AROME and

11 observed after the identification of the various MCS regions. In spite of the fact that

12 AROME simulates a smaller system, located further inland, the applied criteria show that

13 the model is able to simulate organized convection. One of the major interests of this

14 technique is to compare the different MCS regions by overcoming the error in the

15 simulated location of MCSs as observed in Figure 3. As a result, a statistical comparison

16 between in situ data and AROME simulations is made possible in a given dynamical

17 environment and temperature range.

18 4) Microphysical parameters of observed clouds.

19 In this section, observations of the 2015 HAIC field campaign are analyzed in light of the

20 contextualization detailed in section 3 . In the context of ICI, particular attention is paid to 
1 the behavior of TWC, $\mathrm{N}$ and their relationships. The sampled ice crystals are also studied

2 through the analysis of their mass-diameter relationship and MMD.

\section{4.1) TWC}

4 TWC is a key parameter to examine since it is at the source of an ICI flight incident.

5 TWC has to be high up along a long enough path for substantial ice accretion on aircraft

6 engines or instruments to occur. Moreover, it is directly related to AROME ICE3

7 prognostic variables.

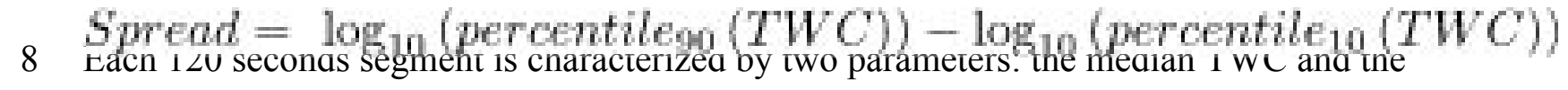

9 spread of TWC within the segment. This spread is computed from percentile 10 and

1090 as:

11 This measure enables the removal of extreme and unusual values within the segment and

12 the characterization of the spread of TWC which spans over several orders of magnitude.

13 High median TWC with low spread segments could be favorable to hazardous ICI. The

14 highest values of TWC are found in the convective regions (Figure 4a) for temperatures

15 as low as $-30^{\circ} \mathrm{C}$, with relatively low spread. Such conditions may be attributed to

16 convective updrafts where water vapor condenses. At the $-45^{\circ} \mathrm{C}$ level, spread increases

17 and TWC decreases, although high values can occasionally be encountered. This could be

18 attributed to the weaker updrafts unable to sustain large crystals at this level or to the

19 detrainment and entrainment processes (Kain \& Fritsch 1990).

20 In other regions of the system (Figure $4 \mathrm{~b}$ and $\mathrm{c}$ ), the same temperature dependency of 
1 TWC exists: higher TWC can generally be found at the lowest levels of the cloud in 2 agreement with Heymsfield et al. (2017) for tropical clouds. They argue that tropical 3 stratiform clouds are mainly composed of small ice crystals maximizing the deposition

4 process because of their low fall speed velocities in a moist environment. The measures 5 of TWC of Heymsfield et al. (2017) are much lower however than those found in the 6 HAIC stratiform clouds and may rather correspond to the values in cirriform regions.

7 High TWC in the stratiform regions may be due to both detrainment of high TWC from 8 the convective region and the mesoscale ascents, generally more vigorous at the lower 9 levels (Gamache \& Houze, 1985), enabling the maintenance of the falling crystals and 10 the accumulation of ice.

11 TWC tends to decrease the further it is away from convection: cirriform regions (Figure $124 c$ ) have lower TWC than stratiform regions (Figure 4b) which have lower TWC than 13 convective regions (Figure 4a). Such a decrease in TWC was already pointed out by 14 Lawson et al. (1998) and Protat et al. (2016). One may also argue that the ice content 15 source through deposition process or heterogeneous nucleation in the stratiform and 16 cirriform regions is less efficient than the loss by sedimentation or sublimation. In the 17 meantime, spread within segments increases as the distance from convective core 18 increases.

19 In stratiform regions, the spread is slightly higher at the $-30^{\circ} \mathrm{C}$ level, though it shows a 20 larger variability in comparison with the convective regions. In the cirriform regions, 21 spread is higher at $-10^{\circ} \mathrm{C}$ because cirriform clouds are generally hardly maintained at 
1 these lower altitudes but rather maintained aloft thanks to ascents produced by radiative 2 effects (Gasparini et al. 2019, Wall et al. 2020).

3 Interesting extreme segments with high median TWC and low spread are found inside the

4 stratiform clouds and more rarely in cirriform clouds. Most of these segments are found 5 at the $-10^{\circ} \mathrm{C}$ level, but some of them can be found at the $-30^{\circ} \mathrm{C}$ or the $-45^{\circ} \mathrm{C}$ level. These

6 segments with high TWC and low spread aloft may be particularly favorable to ICI. In

7 stratiform regions, sustained TWC of about $2.5 \mathrm{~g} / \mathrm{m}^{3}$ and $1 \mathrm{~g} / \mathrm{m}^{3}$ with low spread were

8 sampled at the $-30^{\circ} \mathrm{C}$ and $-45^{\circ} \mathrm{C}$ levels, respectively. These particular segments were

9 individually examined, and correspond to a relative diversity of situations in terms of 10 MCS life cycles or land/sea environments.

\section{4.2) Concentration number}

12 The same analysis as for TWC is applied to concentration number (N) and is shown in

13 Figure 4. The highest concentrations are found in MCS convective regions (Figure 4d)

14 due to the formation of new ice hydrometeors in convective updrafts. These crystals may

15 be formed by heterogeneous nucleation (Hoose and Möhler, 2012). The strong dynamic

16 and numerous hydrometeor interactions inside convective regions can however also

17 induce other processes of ice formation such as the glaciation of supercooled liquid water

18 (Stith et al. 2004), and the formation of secondary ice (Korolev et al., 2020).

19 As for TWC, and as observed by Lawson et al. (2019) in mid-latitude continental anvils,

$20 \mathrm{~N}$ tends to decrease when moving away from convection. Gamache (1990) suggested that 
1 the majority of ice hydrometeors are brought from convective updrafts and are diluted in

2 a larger volume due to transportation, leading to a concentration decrease.

3 Aggregation and deposition processes make the larger crystal concentration increase at

4 the expense of the smaller one, and sedimentation brings them to lower levels. In

5 addition, aggregation becomes more efficient as temperature increases (Kajikawa \&

6 Heymsfield, 1989), resulting in an enhancement of this concentration sink.

7 As for TWC, high $\mathrm{N}$ with low spread can be found especially at $-30^{\circ} \mathrm{C}$ and $-45^{\circ} \mathrm{C}$ in the

8 cirriform and in the stratiform regions (Figure $4 \mathrm{e}$ and $\mathrm{f}$ ). As a result, sustained median $\mathrm{N}$

9 higher than $10^{5} \mathrm{~m}^{-3}$ are occasionally found. These segments are the same identified with

10 high TWC and are hence of a particular interest in the context of ICI.

\section{4.3) Link between TWC and Concentration}

12 To study the relationship between TWC and N, in the context of ICI, only stratiform and

13 cirriform regions are considered. As a result of aggregation and sedimentation in these

14 regions, a majority of aggregates are expected to be found at the $-10^{\circ} \mathrm{C}$ and $-30^{\circ} \mathrm{C}$ levels

15 (Barnes \& Houze 2014; Lawson et al. 2010).

16 A strong relationship exists between these two parameters as shown in Figure 5 where

17 each dot corresponds to the median value of $\mathrm{N}$ and TWC in each segment. Linear

18 regression on a logarithmic scale between these two variables at each temperature level

19 results in high correlation $\left(r=0.82\right.$ at $-10^{\circ} \mathrm{C}, \mathrm{r}=0.94$ at $-30^{\circ} \mathrm{C}$ and $\mathrm{r}=0.95$ at $\left.-45^{\circ} \mathrm{C}\right)$. Such a

20 correlation level has already been observed in Mediterranean convective systems 
1 (Taufour et al., 2018). The lower correlation at the $-10^{\circ} \mathrm{C}$ level is explained by a steeper

2 increase of $\mathrm{N}$ for higher TWC compared to lower ones. The TWC/N scatter plot is also

3 organized according to the temperature. Deposition and aggregation processes could

4 explain such a tendency.

5 The relationship between $\mathrm{N}$ and $\mathrm{r}$ for snow proposed by Caniaux (1993) (Equation 4 and

6 6) and implemented in ICE3 is shown by the black line in Figure 5. The behavior of this

7 relationship is in opposition with the observations.

8 Houze et al. (1979) and Heymsfield (2003) proposed an exponential temperature

9 dependency parameterization of $\lambda$ assuming a Marshall-Palmer shape for the PSD (see

10 section 6.4). Although Heymsfield (2003) proposed generally higher values for $\lambda$ than

11 Houze et al. (1979) the behavior of these two parameterizations is similar. Assuming the

12 temperature dependent parameterization of $\lambda$ from Houze et al. (1979) and using

13 Equation 4, N and TWC are linked with a relatively good agreement in the observations.

14 This parameterization overestimates (resp. underestimates) concentration at the $-30^{\circ} \mathrm{C}$

15 and $-45^{\circ} \mathrm{C}\left(\right.$ resp. $-10^{\circ} \mathrm{C}$ ) levels but reproduces well the increase in $\mathrm{N}$ with TWC.

\section{4.4) Mass-diameter relationship coefficients (a, b)}

17 As detailed in section 2.1, a pair of $\left(\mathrm{a}^{*}, \mathrm{~b}^{*}\right)$ values of mass-size relationships (Equation 1 )

18 are available for each PSD. The median of each parameter in each segment is computed

19 and shown in Figures 6a and $\mathrm{b}$. These parameters give integrated information about the

20 crystal density and are strongly linked. 
1 Mass size parameters depend on altitude, and both $a^{*}$ and $b^{*}$ have the same behavior and

2 decrease as temperature decreases (Schmitt and Heymsfield, 2010). The comparison

3 between obtained values in stratiform regions and the literature suggests that anvils are

4 mainly composed of aggregates (Locatelli \& Hobbs, 1974; Cox, 1988; Lawson et al.,

5 2010; Heymsfield et al., 2002). Convective regions have slightly higher mass size

6 parameters at the $-10^{\circ} \mathrm{C}$ and $-45^{\circ} \mathrm{C}$ levels than cirriform and stratiform regions. It may be

7 the result of a higher proportion of rimed ice or graupel for the $-10^{\circ} \mathrm{C}$ level and of more

8 pristine ice, or of different crystal shapes for the $-45^{\circ} \mathrm{C}$ level. Overall however, as with

9 stratiform and cirriform regions, aggregates seem the most represented hydrometeors in

10 convective regions. The flight sampling strategy used during the HAIC field campaign

11 where graupel was avoided as much as possible could be a possible reason for this

12 behavior.

\section{4.5) MMD}

14 As found by Leroy et al. (2017), the MMD increases with temperature (Figure 6c) and

15 therefore smaller crystals account for a greater part of total mass at higher altitudes. This

16 phenomenon can be explained by sedimentation and the gradual growth of crystals by

17 aggregation and deposition and a more efficient aggregation for higher temperatures

18 (Kajikawa \& Heymsfield, 1989).

19 At the $-10^{\circ} \mathrm{C}$ level, convective regions have slightly lower MMDs compared to stratiform

20 regions, which may be due to the formation of new small ice hydrometeors consistent

21 with the higher concentrations found in section 4.2. On the contrary, stratiform ice 
1 crystals at lower levels are not formed in situ but mostly result from lifted and detrained

2 particles of the convective regions which then sediment, aggregate and are subject to

3 deposition. At the $-30^{\circ} \mathrm{C}$ level, MMDs are generally similar between the convective,

4 stratiform and cirriform regions which could be the result of detrainment. In contrast, at -

$545^{\circ} \mathrm{C}$, as ascent strength decreases from the convective to the stratiform and cirriform

6 regions, the largest hydrometeors cannot be maintained aloft, and MMD decreases.

\section{5) Evaluation of AROME-ICE3 with respect to observations}

8 For this evaluation, all outputs from AROME are considered on the same days as HAIC

92015 flight days. For each flight, convective cells that are both similar and geographically

10 close to the one sampled by the aircraft, are identified and manually tracked.

11 Characteristics of each sub-region of the MCS are compared to the in situ data by using

12 the contextualization method described in section 3. For both TWC and concentration

13 additional temperature levels are added to identify possible biases in the simulated cloud

14 vertical extent. Little supercooled cloud water was found in the simulated systems by

15 AROME at temperatures colder than $-10^{\circ} \mathrm{C}$. Graupel contents represent about $30 \%$ of the

16 mean TWC in the stratiform region at $-10^{\circ} \mathrm{C}$, but only $15 \%$ and $10 \%$ at $-30^{\circ} \mathrm{C}$ and $-45^{\circ} \mathrm{C}$

17 respectively (mean vertical microphysical profiles is shown in supplement S4).

18 Microphysical properties in the model are strongly controlled by the dynamical and

19 thermodynamical environment. The AROME simulation is initialized and forced at the

20 boundaries by the ARPEGE which has a full assimilating system based on Veersé and 
1 Thépaut (1998). A relatively good description of the large scale environment can be

2 assumed. Evaluating in depth the cloud dynamics and thermodynamic is a hard task since

3 few data are available. Nevertheless, an acceptable consistency was found between the

4 mean, percentiles 90 and 95 of the simulated vertical velocities of the convective region

5 and those sampled by RASTA (see supplement S3). Temperature profiles sampled by

6 Falcon-20 were also found to be consistent with AROME (see supplement S3).

\section{5.1) $\mathrm{TWC}$}

8 TWC is a key parameter in ICE3 as the mass mixing ratio of each species are the only

9 prognostic variables. Similarly to Figure 4, Figure 7 is built from AROME outputs, in

10 which each point represents the median and the spread of a given microphysical

11 parameter for the MCS sub-regions at the selected times. For comparison, observed

12 median and extreme values are superimposed.

13 AROME is able to reproduce the main observed behavior of TWC, in particular an

14 increase in TWC with the temperature, and a decrease when moving away from

15 convective regions. Median values of TWC are of the same order of magnitude as the

16 observed ones, though slightly too low, especially aloft. The spread in AROME is higher

17 than observed. The fact that the whole sub-region is taken into account in AROME and

18 not only a smaller part as for the observed segments explains this higher spread.

19 AROME does not simulate high enough TWC in altitude in convective towers, especially

20 near $-30^{\circ} \mathrm{C}$. As the cirriform clouds are rather found at cold temperatures (cf. 
1 Introduction), TWC decreases and spread increases for temperatures higher than $-10^{\circ} \mathrm{C}$.

2 The variability is too high compared to the observations and cases of high TWC aloft are

3 very rare, especially in the stratiform and cirriform regions. The highest values are lower

4 than the observed ones, especially in the stratiform regions. As a result, ICE3 does not

5 seem able to produce satisfying ICI conditions in the stratiform and cirriform regions.

\section{$6 \quad 5.2)$ Concentration}

7 In ICE3, concentration is entirely diagnostic (see section 2.2) and is hereafter derived

8 from the sum of all ice PSD and as in observations over diameters larger than $125 \mu \mathrm{m}$.

9 The order of magnitude of simulated concentration (Figure 7d, e and f) is generally

10 underestimated by more than a factor of 10 and the tendencies of concentration with

11 temperature and MCS sub-region are in opposition with those observed (Figure 4d, e and

12 f): the concentration slightly increases while moving away from convection. The

13 dispersion is generally very low. These differences are the result of the parameterization

14 of snow concentration (Equation 6, Figure 5).

\section{5.3) Mass diameter parameters (a, b)}

16 Even if the separation of the different ice hydrometeor types in a given observed ice PSD

17 is possible (Protat et al. 2011), such estimations are not available in our observational

18 dataset. For the sake of comparison, similar estimation of $\left(a^{*}, b^{*}\right)$ as the ones of Leroy et 
1 al (2017) (see Section 2.1) are performed with AROME outputs. The complete ice PSD is 2 reconstructed by adding up the PSD for each ICE3 ice species computed from Equation 33.

4 A linear regression between $\log \left(\frac{M S D(D)}{n(D)}\right)$ and $\log (D)$ is then applied. Using Equations

51 and 2, the intercept and the slope of this regression correspond respectively to a model

6 estimate of $\log \left(\mathrm{a}^{*}\right)$ and $\mathrm{b}^{*}$.

7 AROME's $\left(a^{*}, b^{*}\right)$ parameters are in relatively good agreement with the ones observed

8 (Figure 6) which are computed from the observations (Section 2.1). Convective regions

9 show slightly higher values, which could correspond to a higher proportion of graupel

10 particles. The avoidance of graupel in the flight plan of the HAIC field campaign could

11 also be partly responsible of this bias however (see Section 2.1).

\section{5.4) MID}

13 MMD is also computed from the AROME PSD including all ice species. In ICE3, MMDs

14 are too large by about one order of magnitude (Figure 6c) and thus simulated PSDs are

15 formed from crystals which are too large. Such behavior could be expected as snow

16 concentrations (section 4.3) and $\lambda$ (section 6.4) are too low in the case of high snow

17 content. Changing the shape of the PSD may also impact the MMD estimates and this

18 room for improvement is explored in section 6. Nevertheless, AROME manages to

19 reproduce the variations of the MMD with temperature. 


\section{6) Description of PSD in the stratiform and cirriform regions}

2 TWC and $\mathrm{N}$ are not the only moments used in a bulk microphysical schemes such as

3 ICE3, but several moments of the PSD are involved in the different microphysical

4 processes. For instance the first moment is used in the deposition mass flux. Hence, the

5 calculation of microphysical processes is dependent on the chosen PSD shape.

6 As detailed in section 2.2, the ICE3 scheme implements a generalized gamma with fixed

$7(\alpha=1, v=1)$ parameters leading to a MP law to describe the snow PSD. This choice is

8 questionable. Indeed, Houze et al. (1979) reported that deviations of the PSD from the

9 MP shape are very common. A mode of between diameters of $200 \mu \mathrm{m}$ and $500 \mu \mathrm{m}$ is

10 common in the observed anvil PSD (Ackerman 2015; Leroy et al. 2017; Fontaine et al.

11 2020; Field \& Heymsfield 2003; Wu \& McFarquhar 2016 among others). This section

12 aims at assessing a more suitable law for representing PSD within the stratiform and

13 cirriform clouds of MCS, keeping in mind that the ICE3 implements a generalized

14 gamma law. Therefore additional variability in the PSD shape (and improvement of the

15 microphysical process representation) may be sought either in fixing $\alpha$ and $v$ to a

16 different value or even by varying them with thermodynamical situation.

\section{6.1) On the choice of generalized gamma and moments to fit PSD}

18 Gamma laws were already used to improve the representation of the ice PSD in anvil

19 clouds for NWP (Thompson et al. 2008). The use of a generalized gamma law is rather

20 rare in the literature and gamma or MP laws are generally found more convenient 
1 (Milbrandt \& Yau, 2005; Ziegler, 1985). Field et al. (2005) tried to fit observed PSD with

2 a generalized gamma law and found that this shape was not able to fully catch both the

3 mode for crystals of a few hundreds of $\mu \mathrm{m}$ and the exponential tail as predicted by

4 Westbrook et al. (2004). Still, in the present study generalized gamma shape has been

5 used to fit PSD to stay within the frame of ICE3. In our simulations, the higher fraction

6 of the IWC in the anvil is due to snow (see S4 in the supplement). We therefore mainly

7 seek to improve the description of the snow distribution, here considered as a crystal size

8 larger than $125 \mu \mathrm{m}$.

9 Former studies used different moments to fit PSDs. Field et al. (2005) and Elsaesser et al. 10 (2017) used pairs among moments 2, 3 and 4, and Heymsfield (2002) used moments 1, 2

11 and 6. As several moments are used in ICE3 parameterizations, it is necessary to

12 determine the pairs (or higher order combination) that are the most representative of the

13 whole PSD. Using the methods describe in Appendix A1 and assuming $\alpha=v=1$, three

14 different moment combinations are tested to retrieve $\lambda$ parameter and compared in Figure

15 8. As described in section 2.2 this parameter is physically linked to the proportion of

16 small versus large hydrometeors. $\lambda$ obtained from a linear regression assuming a MP

17 shape for crystals larger than $125 \mu \mathrm{m}$ is taken as a reference. Using moments 3 and 4

18 leads to results very close to this reference with a correlation coefficient of $r=0.97$. A

19 clear difference appears when $\lambda$ is estimated from moments 1 and 2 , even if correlation

20 remains as high as $r=0.81$. This difference can be explained by the fact that this $\lambda$ better

21 fits the smaller crystals parts of the PSD. The four moments method (from 1 to 4 )

22 detailed in Appendix A1 is found to be a good compromise for $\lambda$ to fit the whole 
1 distribution. In this case $\mathrm{r}=0.94$. The four moments method is used hereafter as it equally

2 weighs large and small crystals of each PSD.

\section{6.2) Findling the best compromise for PSD shape parameters}

4 This section aims at finding the best PSD shape parameters for snow. To do so, a measure

5 named "gap" representing the distance between the computed and observed moments is

6 defined (Appendix A.2). The $(\alpha, v)$ pair corresponding to the minimum of this "gap"

7 enables the most accurate moment computation. The studied sample is restricted to PSDs

8 where TWC exceeds $0.1 \mathrm{~g} / \mathrm{m}^{3}$ in the stratiform regions and in the cirriform regions where

9 the air temperature is also above $-30^{\circ} \mathrm{C}$. These regions are mostly composed of snow.

10 Figure 9a displays the ratio (in percentage) of the gap relatively to its absolute minimum

11 in the $\alpha, v$ space. As a result the closer to $100 \%$ this ratio is, the closer this gap value is to

12 the absolute gap minimum. The lower values of the gap are aligned along a straight line

13 which links $\alpha$ to $v$. As a consequence, multiple values of $\alpha$ and $v$ minimize Equation 16.

14 Among them, $\alpha=0.21 v=43.7$ corresponds to the absolute minimum.

15 The specific cases of a MP $(\alpha=v=1)$ and a gamma law $(v=1.3)$ are generally

16 acceptable. The benefit of the "best" generalized gamma shape is illustrated in Figure 9b

17 where the mean observed PSD is fitted with the different retrieved shapes. The MP is

18 unable to reproduce the mode for crystals of a few hundred $\mu \mathrm{m}$. The gamma law is close

19 to the MP but represents this mode. The generalized gamma law compromise is more

20 realistic with a more pronounced mode, a steeper decrease for small crystals (which are 
1 not considered as snow particles here) and a curving for crystals larger than a few

2 hundreds of $\mu \mathrm{m}$ leading to a higher and more realistic proportion of large crystals.

\section{6.3) Temperature dependency of PSD shape}

4 Further investigations may further reduce this distance between observed and theoretical

5 PSD, especially for the case of high TWC, by studying dependency to physical

6 parameters (as proposed by Elsaesser et al. 2017).

7 The process used in section 6.2 is repeated separately on the three different temperature

8 levels. The region of minimum gap evolves, leading to different relationships between $\alpha$

9 and $v$ for the different temperature levels (Figure 10). The MP still gives reasonable

10 agreement at the $-10^{\circ} \mathrm{C}$ temperature level (Figure $10 \mathrm{a}$ ). However aloft, at the $-30^{\circ} \mathrm{C}$ or -

$1145^{\circ} \mathrm{C}$ level the MP is not satisfactory enough to be considered as a good shape

12 compromise (Figure $10 \mathrm{~b}$ and $\mathrm{c}$ ). A temperature-dependent parameterization of the snow

13 PSD shape is thus worth considering. Table III gives the retrieved values of the best $(\alpha, v)$

14 at each temperature level. To ease the analysis dependency with temperature, $v$ values

15 with constant $\alpha(1,0.5$ and 0.25$)$ are included in this Table.

16 The dependency of $\alpha$ and $v$ with TWC has also been investigated, but no clear

17 dependency has been found (not shown).

\section{6.4) Analysis of $\lambda$ for snow}

19 The dependency of $\lambda$ with TWC in the observations is studied in this section. The $\lambda$ 
1 values are recovered with our moment method (A.1) assuming the best shape found in 2 section 6.2 .

3 Linking $\lambda$ to $\mathrm{N}$ using Equation 6 (Caniaux, 1993) induces a link between $\lambda$ and TWC

4 (Equation 7). Figure 11 shows $\lambda$ as a function of TWC values and no such link can be

5 directly observed. Specifically, high values of $\lambda$ for high TWC are possible, while not

6 allowed by the parameterization of Caniaux (1993).

$7 \lambda$ can be linked to temperature (Houze et al., 1979, Heymsfield, 2003) and seems more

8 adapted to our sample. A temperature dependent parameterization of $\lambda$ has already been

9 used in a NWP system (Thompson et al. 2008). As a result, $\lambda$ increases as temperature

10 decreases (Figure 11). Such a dependency can be explained by aggregation (which is in

11 addition supposed to be more efficient as the temperature increases (Kajikawa \&

12 Heymsfield, 1989), deposition and the quicker sedimentation of larger crystals. Setting

13 such a temperature dependency allows the satisfactory diagnosis of concentration using

14 Equation 4 (Figure 5).

15 Nevertheless, these parameterizations cannot reproduce all the $\lambda$ variability as the

16 dispersion around the diagnostic value remains high (Figure 11). Heymsfield (2003) and

17 Field and Heymsfield (2003) argued that this temperature dependency is blurred by the

18 cloud top height. Indeed, larger cloud depths provide more time for sedimentation and

19 aggregation. This could possibly result in different parameterizations depending on the

20 cloud location. Tropical clouds are generally warmer in the troposphere for a given height

21 than mid-latitude or polar clouds. This could partly explain the major differences between 
1 our observation made in the tropics and the one of Houze et al. (1979) made in mid-

2 latitude (Figure 11).

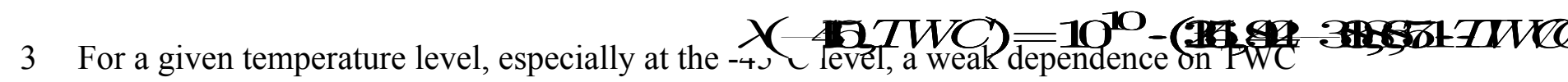

4 can be observed in Figure 11. For TWC between $0.1 \mathrm{~g} / \mathrm{m}^{3}$ and $1 \mathrm{~g} / \mathrm{m}^{3} \lambda$ decreases slightly

5 as the TWC increases. Indeed, a higher TWC results in a higher concentration (Figure 5),

6 which should lead to more collisions between crystals and to more aggregation. However

7 for TWC higher than $\sim 1 \mathrm{~g} / \mathrm{m}^{3}$ scatter plots tend to bend towards a higher $\lambda$ and thus the

8 proportion of smaller crystals is higher. This is particularly interesting in the context of

9 ICI conditions. These hydrometeors could result from the detrainment of a high

10 concentration of crystals formed in the convective updrafts. As $\lambda$ is linked to $\mathrm{N}$ by

11 Equation 4, this bending for high TWC could be linked to the similar one seen in Figure 5

12 especially at the $-10^{\circ} \mathrm{C}$ level. Third order polynomial regressions using the method of

13 least squares are performed between $\lambda$ and TWC for each temperature level (Equation 9)

14 and highlight this dependency.

15

16 Hence a new formulation of $\lambda$ based on the temperature level and the TWC may be

17 proposed.

18 7) Conclusion and outlook

19 This study aimed at analyzing the microphysical characteristics of favorable conditions of

20 ICI and the behavior of the operational mesoscale model AROME for their simulation. 
1 The contextualization method used in this study for both observations and model outputs

2 has enabled an in-depth analysis of the in situ observations of the HAIC 2015 field

3 campaign and the assessment of AROME using the ICE3 microphysical scheme. With

4 this comparison method, general microphysical behaviors of tropical MCSs have been

5 identified.

6 Firstly, getting closer to convective towers, TWC and N increase. These two parameters

7 are strongly linked at each temperature level, and N increases when TWC increases.

8 Multiple microphysical parameters were found to depend on temperature. When the

9 temperature decreases, the TWC, general mass-diameter parameters $\left(\mathrm{a}^{*}, \mathrm{~b}^{*}\right)$ and MMD

10 decrease, while $\lambda$ increases. Particular flight segments potentially favorable to the

11 occurrence of ICI events with high and sustained TWC (and N) were identified in the

12 stratiform and cirriform regions.

13 Some of the microphysical characteristics simulated in AROME are in agreement with

14 our observations. Indeed, AROME is able to reproduce a decrease of general mass-

15 diameter parameters $\left(a^{*}, b^{*}\right)$, MMD and TWC when the temperature decreases or the

16 TWC decrease as they get further away from convective regions.

17 The snow concentration diagnostic derived from the hypothesis of Caniaux (1993) has

18 been proven to be unsatisfactory as forcing an erroneous anti-correlation between TWC

19 and $\mathrm{N}$. It leads to the underestimation of $\mathrm{N}$ by a factor 10 and to excessively large

20 MMDs. As a result, AROME is not able to simulate the sustained high TWC conditions

21 at high altitudes, expected in the case of ICI, as crystals which are too big may sediment 
1 too quickly.

2 The microphysical evaluation of ICE3 carried out in this paper highlights biases and

3 proposes some modifications of the scheme that could help the operational model

4 AROME to better forecast ICI conditions.

5 Assuming a generalized gamma law, the PSD of the stratiform and of the middle to lower

6 region of cirriform clouds has been investigated. We proved that the MP law is an

7 acceptable approximation at the $-10^{\circ} \mathrm{C}$ temperature level but it can be supplanted by the

8 widely used gamma law (Elsaesser et al 2017; Field et al. 2005; Heymsfield 2003)

9 especially at higher altitude. An even better description of higher and lower moments is

10 possible using a generalized gamma law. A new parameterization of $\lambda$, taking into

11 account its dependence on temperature (and eventually by adding a weak TWC

12 dependency) as proposed in section 6.4 could be implemented in bulk microphysical

13 schemes (Thompson et al. 2008). Better describing the snow distribution in

14 microphysical schemes could strongly aid a better representation of concentration and of

15 some processes such as snow sedimentation, aggregation or deposition of vapor on snow

16 for example. The use of a generalized gamma law may enable to compute more

17 accurately some microphysical processes where calibration factors are involved. A

18 positive impact on microphysical schemes with more than one moment is likely.

19 To implement in microphysical schemes the temperature dependencies found for $\lambda$, $\alpha$ and

$20 v$, relationships found in this article have to be extrapolated to other temperatures with

21 caution and the use of additional datasets may be required (Houze et al. 1979; 
1 Heymsfield et al. 2003). Using a process-based determination of $\lambda$ (Mitchell (1988,

2 1991)) could be even more realistic and is not temperature dependent.

3 Using the proposed parameterization elsewhere other than in French Guiana seems

4 possible and may improve the realism of AROME for other types of weather such as

5 mid-latitude fronts or heavy precipitating Mediterranean events (Taufour et al. 2018) but

6 may vary in function of the location. In addition to the reasons evoked in section 6.4, the

7 variability of $\mathrm{CCN}$ and ice freezing nuclei number and types may affect the microphysics

8 of cloud, the PSD of ice and thus $\mathrm{N}, \lambda, \alpha$ and $v$.

9 An enhanced description of pristine ice may also improve the realism of ICI conditions in

10 AROME. As summarized in section 2.2, the pristine ice diagnostic is deduced from

11 Meyers et al. (1992) using supersaturation over ice. This latter is kept artificially low

12 however because it is reduced by an adjustment to the saturation, and hence pristine ice

13 concentration is kept unrealistically low.

14 The 2-moment microphysical scheme LIMA (Liquid Ice Multiple Aerosols, Vié et al.

15 2016), which is under evaluation in AROME and currently used for research purposes

16 (Taufour et al., 2018, Ducongé et al., 2020) may improve the representation of pristine

17 ice. In particular, it implements a prognostic concentration for pristine ice and cloud

18 water particles, has a prognostic representation of aerosols and their interactions with

19 clouds, and allows supersaturation over ice to develop freely. This should enhance the

20 description of cloud water and its depletion, the description of ice and of the deposition

21 process. Secondary ice production processes (Korolev et al. 2020) can then be taken into 
1 account and may help to correct some possible biases of single moment schemes. LIMA

2 enables the use of a second moment for snow, and its potential benefit over our proposed

3 parameterization may be worth documenting.

4 In a following paper, sensitivity to the derived parameterizations will be explored to

5 enhance the forecast of ICI conditions with AROME.

6 Acknowledgments:

7 This work was partially supported by CNES. The experimental research underlying this

8 modeling study has received funding (HAIC-HIWC project) from (i) the European

9 Union's Seventh Framework Program in research, technological development and

10 demonstration under grant agreement no. ACP2-GA-2012-314314, (ii) the European

11 Aviation Safety Agency (EASA) Research Program under service contract no.

12 EASA.2013.FC27, and (iii) the Federal Aviation Administration (FAA), Aviation

13 Research Division, and Aviation Weather Division, under agreement CON-I-1301 with

14 the Centre National de la Recherche 30 Scientifique. Funding for the support flight

15 project was also provided by the NASA Aviation Safety Program, the Boeing Co., and

16 Transport Canada. Additional support was also provided by Airbus SAS Operations,

17 Science Engineering Associates, the Bureau of Meteorology, Environment Canada, the

18 National Research Council of Canada, and the universities of Utah and Illinois. The

19 authors thank the SAFIRE facility for the scientific airborne operations. SAFIRE

20 (http://www.safire.fr) is a joint facility of CNRS, Météo-France, and CNES dedicated to 
1 flying research aircraft.

2 This scientific project could not have been possible without the special investment of its

3 scientific director, Eric Defer. The analysis of the data set used in this study was made

4 possible thanks to the work of Alfons Schwarzenboeck. We are also particularly grateful

5 to Ghislain Faure for his technical support on AROME.

6 Appendix

7 Generalized gamma law fits method using distribution moments

8 In bulk microphysical schemes only moments of the distribution computed through

9 Equation 11 are used as prognostic variables and feed the various parameterizations.

10 Doing so enables considerable reductions in the calculation costs (Tripoli et al., 1988).

11 Using several moments of the observed PSD, the objective of this section is to propose a

12 methodology to fit the observed PSD with a generalized gamma distribution.

\section{A.1) Determination of $\lambda$}

15

$$
M(n)=\int_{0}^{+\infty} n(D) D^{2} d D
$$

16 The generalized gamma distribution is defined using a triplet of parameters $(\alpha, v, \lambda)$, any 
1 moment of the PSD is then linked to this triplet through:

$2 M(n)=\frac{G(\alpha, \nu, b)}{\lambda^{n}}$

3 Glefined in Equation 5.

4 By using Equation 11 twice for two different moments $n$ and $m, \lambda$ can be derived:

5

$$
\lambda=\left(\frac{M(n)}{M(m)} \cdot \frac{\Gamma\left(\nu+\frac{m}{\alpha}\right)}{\Gamma\left(\nu+\frac{n}{\alpha}\right)}\right)^{\frac{1}{m-n}}
$$

6 Different moments can be chosen for estimating $\lambda$. To put weight on more moments,

7 Equation 11 can be used for two pairs of moments, e.g. $(n, m)=(1,2)$ and $(n, m)=(3,4)$.

8 In order for the weights to be equally distributed on a broad range of crystal diameters:

9

10 Note that moments 5 and 6 were not used as many PSDs were too noisy for the largest

11 crystals. We call this method the "four moments method".

\section{A.2) Determination of the best $(\alpha, v)$ pairs by fitting observed PSD}

13 The moment of the observed PSD, ${ }_{M}^{1}$ merically $(\boldsymbol{n}$ integrated. For each PSD p, the

14 corresponding $\lambda$ is computed using the four moments method (see A.1) and assuming 
1 different values of $\alpha$ and $v$. The theoretical moments of the PSD $\boldsymbol{P}$

\section{$\left(M_{p}^{\text {th }}\right.$ smputite $)$}

2 using Equation 10. The theoretical concentration, $0^{\text {th }}$ moment, is computed using

3 Equation 4 in which $\mathrm{r}$ is taken from the IKP-2. The values of the mass diameter

4 parameters $(a, b)$ are set constant to the ones used in AROME for snow (cf. Table I).

\section{$p$}

5 The difference between the observed and the theoretical $\mathrm{n}^{\text {th }}$ moment normalized by its

6 concentration $\mathrm{N}$ for each PSD is computed as:

7

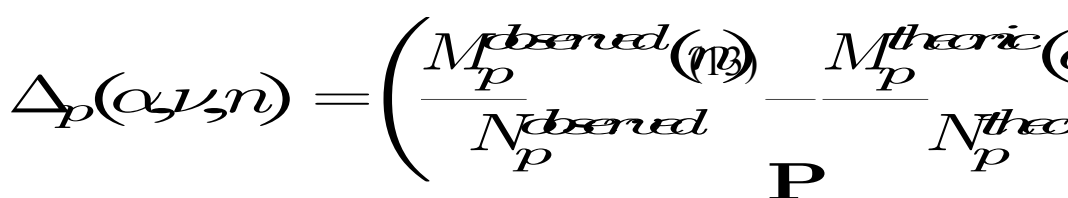

8 This process is repeated for moments from 1 to 4 , for the K PSDs of the ensemble of PSD

9 (see section 6.2 for definition) and for values of $\alpha$ and $v$ ranging (logarithmically) from

$10 \quad 0.1$ to 3 and 0.1 to 75 over 50 values.

11 Because the order of magnitude of each moment is different and depends on the values of $12 \alpha$ and $v$, the same weight is given to each moment by normalizing :

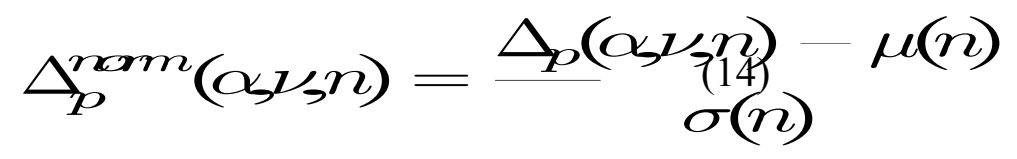

14 Where calld are 2 (rie mean and the standard deviation of actuss the number of PSD (K)

15 belonging to , times the 50 times 50 values of tested $\alpha$ and $v$ values.

16 The $(\alpha, v)$ pairs which minimize:

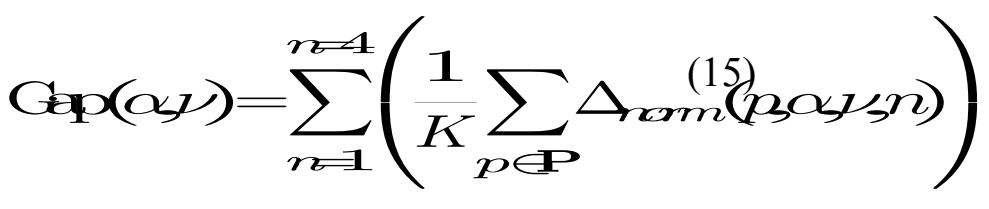


1 are considered as the best fit.

\section{Supporting information}

3 A supplement related to this article is available. It is composed of four sections S1 to S4

4 with a total of eleven additional figures.

5 S.1 Qualitative evaluation of the consistency of the convective, stratiform, cirriform

$6 \quad$ PCT/IR classification used in the observations using RASTA reflectivity measurements

7 S.2 Qualitative evaluation of the consistency of the convective, stratiform, cirriform

8 classifications between model and observations

9 S.3 Evaluation of the simulated thermodynamical and dynamical environment using

10 ancillary HAIC data

11 S.4 Contribution of each cloud species mass content to TWC

\section{Bibliography}

13 [1] A. Ackerman, A. Fridlind, A. Grandin, F. Dezitter, M. Weber, J. Strapp, and A.

14 Korolev. High ice water content at low radar reflectivity near deep convection: Part

15 ii. evaluation of microphysical pathways in updraft parcel simulations. 2015.

16 [2] R. F. Adler, R. A. Mack, N. Prasad, I. M. Hakkarinen, and H. M. Yeh. Aircraft

17 microwave observations and simulations of deep convection from 18 to 183 ghz. 
1 part i: Observations. Journal of Atmospheric and Oceanic Technology, 7(3):377-391, 21990.

3 [3] B. A. Albrecht. Aerosols, cloud microphysics, and fractional cloudiness. Science, $4 \quad$ 245(4923):1227-1230, 1989.

5 [4] H. C. Barnes and R. A. Houze. Precipitation hydrometeor type relative to the

6 mesoscale airflow in mature oceanic deep convection of the madden-julian

7 oscillation. Journal of Geophysical Research: Atmospheres, 119(24):13-990, 2014.

8 [5] D. Baumgardner, S. Abel, D. Axisa, R. Cotton, J. Crosier, P. Field, C. Gurganus, A.

9 Heymsfield, A. Korolev, M. Kraemer, et al. Cloud ice properties: In situ measurement

10 challenges. Meteorological monographs, 58:9-1, 2017.

11 [6] B. C. Bernstein and C. Le Bot. An inferred climatology of icing conditions aloft, 12 including supercooled large drops. part ii: Europe, asia, and the globe. Journal of 13 applied meteorology and climatology, 48(8):1503-1526, 2009.

14 [7] S. Bloom, L. Takacs, A. Da Silva, and D. Ledvina. Data assimilation using 15 incremental analysis updates. Monthly Weather Review, 124(6):1256-1271, 1996.

16 [8] D. Bouniol, R. Roca, T. Fiolleau, and D. E. Poan. Macrophysical, microphysical, and 17 radiative properties of tropical mesoscale convective systems over their life cycle. 18 Journal of Climate, 29(9):3353-3371, 2016. 
1 [9] M. Boyé, G. Cabaussel, and Y. Perrot. Climatologie: Atlas des départements

2 français d'outre-mer-iv-la guyane. ORSTOM, Paris, 1979.

3 [10] M. Bravin and J. W. Strapp. A continuing investigation of diurnal and location

4 trends in an ice crystal icing engine event database. SAE International Journal of

5 Advances and Current Practices in Mobility, 2(2019-01-1964):90-105, 2019.

6 [11] P. Brousseau, Y. Seity, D. Ricard, and J. Léger. Improvement of the forecast of 7 convective activity from the arome-france system. Quarterly Journal of the Royal 8 Meteorological Society, 142(699):2231-2243, 2016.

9 [12] J. M. Brown. Mesoscale unsaturated downdrafts driven by rainfall evaporation:

10 A numerical study. Journal of the Atmospheric Sciences, 36(2):313-338, 1979.

11

13 [13] R. Bubnová, G. Hello, P. Bénard, and J.-F. Geleyn. Integration of the fully elastic

14 equations cast in the hydrostatic pressure terrain-following coordinate in the

15 framework of the arpege/aladin nwp system. Monthly Weather Review,

16 123(2):515-535, 1995.

17 [14] G. Caniaux. Paramétrisation de la phase glace dans un modèle non

18 hydrostatique de nuage: application à une ligne de grains tropicale. $\mathrm{PhD}$ thesis, 
11993.

2 [15] J.-P. Chaboureau and J.-P. Pinty. Validation of a cirrus parameterization with

3 meteosat second generation observations. Geophysical research letters, 33(3), 2006.

4 [16] D. Chung, G. Matheou, and J. Teixeira. Steady-state large-eddy simulations to

5 study the stratocumulus to shallow cumulus cloud transition. Journal of the

6 atmospheric sciences, 69(11):3264-3276, 2012.

7 [17] R. Cifelli and S. A. Rutledge. Vertical motion, diabatic heating, and rainfall

8 characteristics in north australia convective systems. Quarterly Journal of the Royal

9 Meteorological Society, 124(548):1133-1162, 1998.

10 [18] A. A. Costa, W. R. Cotton, R. L. Walko, R. A. Pielke Sr, and H. Jiang. Sst

11 sensitivities in multiday toga coare cloud-resolving simulations. Journal of the

12 Atmospheric Sciences, 58(3):253-268, 2001.

13 [19] P. Courtier, C. Freydier, J. Geleyn, F. Rabier, and M. Rochas. The arpege project

14 at météo-france, ecmwf workshop, european center for medium-range weather

15 forecast. Reading, England, 1991.

16 [20] P. Coutris. Analyse des propriétés dimensionnelles et massiques des cristaux de

17 glace pour l'étude des processus microphysiques dans les systèmes convectifs à

18 méso-échelle. PhD thesis, 2019. 
1 [21] G. Cox. Modelling precipitation in frontal rainbands. Quarterly Journal of the

2 Royal Meteorological Society, 114(479):115-127, 1988.

3 [22] J. Cuxart, P. Bougeault, and J.-L. Redelsperger. A turbulence scheme allowing for

4 mesoscale and large-eddy simulations. Quarterly Journal of the Royal

5 Meteorological Society, 126(562):1-30, 2000.

6 [23] C. Davison, J. MacLeod, J. Strapp, and D. Buttsworth. Isokinetic Total Water

7 Content Probe in a Naturally Aspirating Configuration: Initial Aerodynamic Design

8 and Testing, 2008.

9 [24] C. R. Davison, J. W. Strapp, L. E. Lilie, T. P. Ratvasky, and C. Dumont. Isokinetic

10 TWC Evaporator Probe: Calculations and Systemic Error Analysis, 2016.

11 [25] J. Delanoë, A. Protat, D. Bouniol, A. Heymsfield, A. Bansemer, and P. Brown. The

12 characterization of ice cloud properties from doppler radar measurements. Journal

13 of applied meteorology and climatology, 46(10):1682-1698, 2007.

14 [26] P. J. DeMott and D. C. Rogers. Freezing nucleation rates of dilute solution

15 droplets measured between- 30 and- $40 \mathrm{c}$ in laboratory simulations of natural

16 clouds. Journal of the atmospheric sciences, 47(9):1056-1064, 1990.

17 [27] L. Ducongé, C. Lac, B. Vié, T. Bergot, and J. Price. Fog in heterogeneous

18 environments: The relative importance of local and non-local processes on 
1 radiative-advective fog formation. Quarterly Journal of the Royal Meteorological

2 Society, 2020.

3 [28] J. P. Duvel. Convection over tropical africa and the atlantic ocean during

4 northern summer. part i: Interannual and diurnal variations. Monthly weather

5 review, 117(12):2782-2799, 1989.

6 [29] G. S. Elsaesser, A. D. Del Genio, J. H. Jiang, and M. van Lier-Walqui. An improved

7 convective ice parameterization for the nasa giss global climate model and impacts

8 on cloud ice simulation. Journal of Climate, 30(1):317-336, 2017.

9 [30] G. Faure, P. Chambon, and P. Brousseau. Operational implementation of the

10 arome model in the tropics: Multiscale validation of rainfall forecasts. Weather and

11 Forecasting, 35(2):691-710, 2020.

12 [31] P. Field, A. Heymsfield, and A. Bansemer. Shattering and particle interarrival

13 times measured by optical array probes in ice clouds. Journal of Atmospheric and

14 Oceanic Technology, 23(10):1357-1371, 2006.

15 [32] P. Field, R. Hogan, P. Brown, A. Illingworth, T. Choularton, and R. Cotton.

16 Parametrization of ice particle size distributions for mid-latitude stratiform cloud.

17 Quarterly Journal of the Royal Meteorological Society: A journal of the atmospheric

18 sciences, applied meteorology and physical oceanography, 131(609):1997-2017,

192005. 
1 [33] P. R. Field and A. J. Heymsfield. Aggregation and scaling of ice crystal size

2 distributions. Journal of the atmospheric sciences, 60(3):544-560, 2003.

3 [34] E. Fontaine, A. Schwarzenboeck, J. Delanoë, W. Wobrock, D. Leroy, R. Dupuy, C.

4 Gourbeyre, and A. Protat. Constraining mass-diameter relations from hydrometeor

5 images and cloud radar reflectivities in tropical continental and oceanic convective

6 anvils. 2014.

7 [35] E. Fontaine, A. Schwarzenboeck, D. Leroy, J. Delanoë, A. Protat, F. Dezitter, J. W.

8 Strapp, and L. E. Lilie. Statistical analysis of ice microphysical properties in tropical

9 mesoscale convective systems derived from cloud radar and in situ microphysical

10 observations. Atmospheric Chemistry and Physics, 20(6):3503-3553, 2020.

11 [36] Y. Fouquart and B. Bonnel. Computations of solar heating of the earth's

12 atmosphere: A new parameterization. 1980.

13 [37] C. N. Franklin, A. Protat, D. Leroy, and E. Fontaine. Controls on phase

14 composition and ice water content in a convection-permitting model simulation of a

15 tropical mesoscale convective system. Atmospheric Chemistry and Physics,

16 16(14):8767-8789, 2016.

17 [38] J. F. Gamache. Microphysical observations in summer monex convective and

18 stratiform clouds. Monthly weather review, 118(6):1238-1249, 1990. 
1 [39] J. F. Gamache and R. A. Houze Jr. Mesoscale air motions associated with a

2 tropical squall line. Monthly Weather Review, 110(2):118-135, 1982.

3 [40] J. F. Gamache and R. A. Houze Jr. Further analysis of the composite wind and

4 thermodynamic structure of the 12 september gate squall line. Monthly weather

5 review, 113(8):1241-1260, 1985.

6 [41] B. Gasparini, P. N. Blossey, D. L. Hartmann, G. Lin, and J. Fan. What drives the life

7 cycle of tropical anvil clouds? Journal of Advances in Modeling Earth Systems,

8 11(8):2586-2605, 2019.

9 [42] M. L. Grzych and J. G. Mason. Weather conditions associated with jet engine

10 power loss and damage due to ingestion of ice particles: What we've learned

11 through 2009. In 14th Conference on Aviation, Range and Aerospace Meteorology, 122010.

13 [43] J. Haggerty, E. Defer, A. De Laat, K. Bedka, J.-M. Moisselin, R. Potts, J. Delanoë, F.

14 Parol, A. Grandin, and S. Divito. Detecting clouds associated with jet engine ice

15 crystal icing. Bulletin of the American Meteorological Society, 100(1):31-40, 2019.

16 [44] J. A. Haggerty, A. Rugg, R. Potts, A. Protat, J. W. Strapp, T. Ratvasky, K. Bedka,

17 and A. Grandin. Development of a method to detect high ice water content

18 environments using machine learning. Journal of Atmospheric and Oceanic

19 Technology, 37(4):641-663, 2020. 
1 [45] A. Heymsfield. Ice crystal terminal velocities. Journal of Atmospheric Sciences, 2 29(7):1348 - 1357, 01 Oct. 1972.

3 [46] A. Heymsfield, M. Krämer, N. B. Wood, A. Gettelman, P. R. Field, and G. Liu.

4 Dependence of the Ice Water Content and Snowfall Rate on Temperature, Globally:

5 Comparison of in Situ Observations, Satellite Active Remote Sensing Retrievals, and

6 Global Climate Model Simulations. Journal of Applied Meteorology and Climatology,

$7 \quad$ 56(1):189-215, 012017.

8 [47] A. J. Heymsfield. The characteristics of graupel particles in northeastern

9 colorado cumulus congestus clouds. Journal of the Atmospheric Sciences,

$1035(2): 284-295,1978$.

11 [48] A. J. Heymsfield. Properties of tropical and midlatitude ice cloud particle

12 ensembles. part ii: Applications for mesoscale and climate models. Journal of the

13 atmospheric sciences, 60(21):2592-2611, 2003.

14 [49] A. J. Heymsfield, A. Bansemer, P. R. Field, S. L. Durden, J. L. Stith, J. E. Dye, W.

15 Hall, and C. A. Grainger. Observations and parameterizations of particle size

16 distributions in deep tropical cirrus and stratiform precipitating clouds: Results

17 from in situ observations in trmm field campaigns. Journal of the atmospheric

18 sciences, 59(24):3457-3491, 2002.

19 [50] A. J. Heymsfield and L. M. Miloshevich. Homogeneous ice nucleation and 
1 supercooled liquid water in orographic wave clouds. Journal of the Atmospheric

2 Sciences, 50(15):2335-2353, 1993.

3 [51] C. Hoose and O. Möhler. Heterogeneous ice nucleation on atmospheric aerosols:

4 a review of results from laboratory experiments. Atmospheric Chemistry and

5 Physics, 12(20):9817-9854, 2012.

6 [52] A. Y. Hou, R. K. Kakar, S. Neeck, A. A. Azarbarzin, C. D. Kummerow, M. Kojima, R.

7 Oki, K. Nakamura, and T. Iguchi. The global precipitation measurement mission.

8 Bulletin of the American Meteorological Society, 95(5):701-722, 2014.

9 [53] R. A. Houze. Cloud clusters and large-scale vertical motions in the tropics.

10 Journal of the Meteorological Society of Japan, 60(1), 1982.

11 [54] R. A. Houze. 100 years of research on mesoscale convective systems.

12 Meteorological Monographs, 59:17-1, 2018.

13 [55] R. A. Houze Jr. Stratiform precipitation in regions of convection: A

14 meteorological paradox? Bulletin of the American Meteorological Society, 15 78(10):2179-2196, 1997.

16 [56] R. A. Houze Jr, C.-P. Cheng, C. A. Leary, and J. F. Gamache. Diagnosis of cloud

17 mass and heat fluxes from radar and synoptic data. Journal of the Atmospheric

18 Sciences, 37(4):754-773, 1980. 
1 [57] R. A. Houze Jr, P. V. Hobbs, P. H. Herzegh, and D. B. Parsons. Size distributions of

2 precipitation particles in frontal clouds. Journal of Atmospheric Sciences,

$336(1): 156-162,1979$.

4 [58] Y. Huang, W. Wu, G. M. McFarquhar, X. Wang, H. Morrison, A. Ryzhkov, Y. Hu, M.

5 Wolde, C. Nguyen, A. Schwarzenboeck, et al. Microphysical processes producing high

6 ice water contents (hiwcs) in tropical convective clouds during the haic-hiwc field

7 campaign: Evaluation of simulations using bulk microphysical schemes.

8 Atmospheric Chemistry and Physics Discussions, pages 1-40, 2020.

9 [59] J. G. Hudson and S. S. Yum. Maritime-continental drizzle contrasts in small

10 cumuli. Journal of the atmospheric sciences, 58(8):915-926, 2001.

11 [60] J. S. Kain and J. M. Fritsch. A one-dimensional entraining/detraining plume

12 model and its application in convective parameterization. Journal of the

13 Atmospheric Sciences, 47(23):2784-2802, 1990.

14 [61] M. Kajikawa and A. J. Heymsfield. Aggregation of ice crystals in cirrus. Journal of 15 the atmospheric sciences, 46(20):3108-3121, 1989.

16 [62] E. Kessler. On the distribution and continuity of water substance in

17 atmospheric circulations. In On the distribution and continuity of water substance in 18 atmospheric circulations, pages 1-84. Springer, 1969. 
1 [63] S. A. Klein and D. L. Hartmann. The seasonal cycle of low stratiform clouds.

2 Journal of Climate, 6(8):1587-1606, 1993.

3 [64] A. Korolev, E. Emery, and K. Creelman. Modification and tests of particle probe

4 tips to mitigate effects of ice shattering. Journal of Atmospheric and Oceanic

5 Technology, 30(4):690-708, 2013.

6 [65] A. Korolev and P. Field. Assessment of the performance of the inter-arrival time 7 algorithm to identify ice shattering artifacts in cloud particle probe measurements. 8 Atmospheric Measurement Techniques, 8(2):761-777, 2015.

9 [66] A. Korolev, I. Heckman, M. Wolde, A. S. Ackerman, A. M. Fridlind, L. A. Ladino, R.

10 P. Lawson, J. Milbrandt, and E. Williams. A new look at the environmental conditions

11 favorable to secondary ice production. Atmospheric Chemistry and Physics, 12 20(3):1391-1429, 2020.

13 [67] A. Korolev and B. Sussman. A technique for habit classification of cloud 14 particles. Journal of Atmospheric and Oceanic Technology, 17(8):1048-1057, 2000.

15 [68] A. d. Laat, E. Defer, J. Delanoë, F. Dezitter, A. Gounou, A. Grandin, A. Guignard, J.

16 F. Meirink, J.-M. Moisselin, and F. Parol. Analysis of geostationary satellite-derived

17 cloud parameters associated with environments with high ice water content.

18 Atmospheric Measurement Techniques, 10(4):1359-1371, 2017. 
1 [69] C. Lac, P. Chaboureau, V. Masson, P. Pinty, P. Tulet, J. Escobar, M. Leriche, C.

2 Barthe, B. Aouizerats, C. Augros, et al. Overview of the meso-nh model version 5.4

3 and its applications. Geoscientific Model Development, 11:1929-1969, 2018.

4 [70] S. Lance, C. Brock, D. Rogers, and J. A. Gordon. Water droplet calibration of the 5 cloud droplet probe (cdp) and in-flight performance in liquid, ice and mixed-phase 6 clouds during arcpac. Atmospheric Measurement Techniques, 3(6):1683, 2010.

7 [71] S. Lang, W. Tao, J. Simpson, and B. Ferrier. Modeling of convective-stratiform

8 precipitation processes: Sensitivity to partitioning methods. Journal of Applied

9 Meteorology, 42(4):505-527, 2003.

10 [72] R. Lawson, S. Woods, E. Jensen, E. Erfani, C. Gurganus, M. Gallagher, P. Connolly,

11 J. Whiteway, A. Baran, P. May, et al. A review of ice particle shapes in cirrus formed

12 in situ and in anvils. Journal of Geophysical Research: Atmospheres, 124(17-

13 18):10049-10090, 2019.

14 [73] R. P. Lawson, L. J. Angus, and A. J. Heymsfield. Cloud particle measurements in

15 thunderstorm anvils and possible weather threat to aviation. Journal of aircraft, 16 35(1):113-121, 1998.

17 [74] R. P. Lawson, E. Jensen, D. L. Mitchell, B. Baker, Q. Mo, and B. Pilson.

18 Microphysical and radiative properties of tropical clouds investigated in tc4 and

19 namma. Journal of Geophysical Research: Atmospheres, 115(D10), 2010. 
1 [75] R. P. Lawson, D. O'connor, P. Zmarzly, K. Weaver, B. Baker, Q. Mo, and H.

2 Jonsson. The 2d-s (stereo) probe: Design and preliminary tests of a new airborne,

3 high-speed, high-resolution particle imaging probe. Journal of Atmospheric and

4 Oceanic Technology, 23(11):1462-1477, 2006.

5 [76] C. Lebeaupin Brossier. Étude du couplage océan-atmosphère associé aux

6 épisodes de pluie intense en région méditérannéenne. $\mathrm{PhD}$ thesis, Toulouse 3, 2007.

7 [77] J.-M. Lellouche, E. Greiner, O. Le Galloudec, G. Garric, C. Regnier, M. Drevillon, M.

8 Benkiran, C.-E. Testut, R. Bourdalle-Badie, F. Gasparin, et al. Recent updates to the

9 copernicus marine service global ocean monitoring and forecasting real-time $1 / 12^{\circ}$

10 high-resolution system. Ocean Science, 14(5):1093-1126, 2018.

11

12 [78] D. Leroy, E. Fontaine, A. Schwarzenboeck, and J. Strapp. Ice crystal sizes in high

13 ice water content clouds. part i: On the computation of median mass diameter from

14 in situ measurements. Journal of Atmospheric and Oceanic Technology,

15 33(11):2461-2476, 2016.

16 [79] D. Leroy, E. Fontaine, A. Schwarzenboeck, J. W. Strapp, A. Korolev, G.

17 McFarquhar, R. Dupuy, C. Gourbeyre, L. Lilie, A. Protat, et al. Ice crystal sizes in high

18 ice water content clouds. part ii: Statistics of mass diameter percentiles in tropical

19 convection observed during the haic/hiwc project. Journal of Atmospheric and 
1 Oceanic Technology, 34(1):117-136, 2017.

2 [80] J. D. Locatelli and P. V. Hobbs. Fall speeds and masses of solid precipitation

3 particles. Journal of Geophysical Research, 79(15):2185-2197, 1974.

4 [81] J. S. Marshall and W. M. K. Palmer. The distribution of raindrops with size.

5 Journal of meteorology, 5(4):165-166, 1948.

6 [82] J. Mason, W. Strapp, and P. Chow. The ice particle threat to engines in flight. In

7 44th AIAA Aerospace Sciences Meeting and Exhibit, page 206, 2006.

8 [83] J. G. Mason and M. Grzych. The challenges identifying weather associated with

9 jet engine ice crystal icing. Technical report, SAE Technical Paper, 2011.

10 [84] V. Masson, P. Le Moigne, E. Martin, S. Faroux, A. Alias, R. Alkama, S. Belamari, A.

11 Barbu, A. Boone, F. Bouyssel, P. Brousseau, E. Brun, J.-C. Calvet, D. Carrer, B.

12 Decharme, C. Delire, S. Donier, K. Essaouini, A.-L. Gibelin, H. Giordani, F. Habets, M.

13 Jidane, G. Kerdraon, E. Kourzeneva, M. Lafaysse, S. Lafont, C. Lebeaupin Brossier, A.

14 Lemonsu, J.-F. Mahfouf, P. Marguinaud, M. Mokhtari, S. Morin, G. Pigeon, R. Salgado,

15 Y. Seity, F. Taillefer, G. Tanguy, P. Tulet, B. Vincendon, V. Vionnet, and A. Voldoire.

16 The SURFEXv7.2 land and ocean surface platform for coupled or offline simulation

17 of Earth surface variables and fluxes. Geoscientific Model Development,6:929-960,

18 2013. CC Attribution 3.0 License.Final revised paper also available at

19 http://www.geosci-model-dev.net/6/929/2013/gmd-6-929-2013.pdf. 
1 [85] M. P. Meyers, P. J. DeMott, and W. R. Cotton. New primary ice-nucleation

2 parameterizations in an explicit cloud model. Journal of Applied Meteorology, 3 31(7):708-721, 1992.

4 [86] J. Milbrandt and M. Yau. A multimoment bulk microphysics parameterization.

5 part i: Analysis of the role of the spectral shape parameter. Journal of the

6 atmospheric sciences, 62(9):3051-3064, 2005.

7 [87] D. L. Mitchell. Evolution of snow-size spectra in cyclonic storms. part i: Snow

8 growth by vapor deposition and aggregation. Journal of the atmospheric sciences,

$9 \quad 45(22): 3431-3451,1988$.

10 [88] D. L. Mitchell. Evolution of snow-size spectra in cyclonic storms. part ii:

11 Deviations from the exponential form. Journal of the atmospheric sciences,

$1248(16): 1885-1899,1991$.

13 [89] E. J. Mlawer, S. J. Taubman, P. D. Brown, M. J. Iacono, and S. A. Clough. Radiative

14 transfer for inhomogeneous atmospheres: Rrtm, a validated correlated-k model for

15 the longwave. Journal of Geophysical Research: Atmospheres, 102(D14):16663-

$1616682,1997$.

17 [90] K. I. Mohr and E. J. Zipser. Mesoscale convective systems defined by their 85-

18 ghz ice scattering signature: Size and intensity comparison over tropical oceans and

19 continents. Monthly weather review, 124(11):2417-2437, 1996. 
1 [91] J.-J. Morcrette. Radiation and cloud radiative properties in the european centre

2 for medium range weather forecasts forecasting system. Journal of Geophysical

3 Research: Atmospheres, 96(D5):9121-9132, 1991.

4 [92] R. E. Passarelli Jr. An approximate analytical model of the vapor deposition and 5 aggregation growth of snowflakes. Journal of the Atmospheric Sciences, 35(1):118$6 \quad 124,1978$.

7 [93] J. Pergaud, V. Masson, S. Malardel, and F. Couvreux. A parameterization of dry

8 thermals and shallow cumuli for mesoscale numerical weather prediction.

9 Boundary-layer meteorology, 132(1):83, 2009.

10 [94] J.-P. Pinty and P. Jabouille. A mixed-phase cloud parameterization for use in 11 mesoscale non-hydrostatic model: simulations of a squall line and of orographic 12 precipitations. In Conf. on Cloud Physics, pages 217-220. Amer. Meteor. Soc Everett, 13 WA, 1998.

14 [95] F. Proctor, S. Harrah, G. F. Switzer, J. K. Strickland, and P. J. Hunt. High ice water 15 concentrations in the 19 august 2015 coastal mesoconvective system. In 9th AIAA 16 Atmospheric and Space Environments Conference, page 4370, 2017.

17 [96] A. Protat, D. Bouniol, J. Delanoë, E. O’Connor, P. May, A. Plana-Fattori, A. Hasson, 18 U. Görsdorf, and A. Heymsfield. Assessment of cloudsat reflectivity measurements 19 and ice cloud properties using ground-based and airborne cloud radar observations. 
1 Journal of Atmospheric and Oceanic Technology, 26(9):1717-1741, 2009.

2 [97] A. Protat, J. Delanoë, J. Strapp, E. Fontaine, D. Leroy, A. Schwarzenboeck, L. Lilie,

3 C. Davison, F. Dezitter, A. Grandin, et al. The measured relationship between ice

4 water content and cloud radar reflectivity in tropical convective clouds. Journal of

5 Applied Meteorology and Climatology, 55(8):1707-1729, 2016.

6 [98] A. Protat, G. M. Mcfarquhar, J. Um, and J. Delanoë. Obtaining best estimates for

7 the microphysical and radiative properties of tropical ice clouds from twp-ice in situ

8 microphysical observations. Journal of applied meteorology and climatology,

9 50(4):895-915, 2011.

10 [99] S. Riette. Development of "physical parametrizations with python"(pppy,

11 version 1.1) and its usage to reduce the time-step dependency in a microphysical

12 scheme. Geoscientific Model Development, 13(2):443-460, 2020.

13 [100] R. Roca, T. Fiolleau, and D. Bouniol. A simple model of the life cycle of

14 mesoscale convective systems cloud shield in the tropics. Journal of Climate,

15 30(11):4283-4298, 2017.

16 [101] B. F. Ryan. A bulk parameterization of the ice particle size distribution and the

17 optical properties in ice clouds. Journal of the atmospheric sciences, 57(9):1436-

$181451,2000$. 
1 [102] R. Saunders, J. Hocking, E. Turner, P. Rayer, D. Rundle, P. Brunel, J. Vidot, P.

2 Roquet, M. Matricardi, A. Geer, et al. An update on the rttov fast radiative transfer

3 model (currently at version 12). Geoscientific Model Development, 11(7), 2018.

4 [103] V. S. Schaefer. Condensed water in the free atmosphere in air colder than- 40c.

5 Journal of Applied Meteorology, 1(4):481-488, 1962.

6 [104] C. Schmitt and A. J. Heymsfield. The dimensional characteristics of ice crystal

7 aggregates from fractal geometry. Journal of the Atmospheric Sciences, 67(5):1605-

$81616,2010$.

9 [105] A. Schwarzenboeck, A. Calmels, P. Coutris, J. Delanoe, F. Dezitter, F. Huet, D.

10 Leroy, and A. Protat. Characterization of in-situ measured microphysical properties

11 in high iwc regions during the 2014 and 2015 haic/hiwc international field

12 campaigns. Technical report, 2018.

13 [106] Y. Seity, P. Brousseau, S. Malardel, G. Hello, P. Bénard, F. Bouttier, C. Lac, and V.

14 Masson. The arome-france convective-scale operational model. Monthly Weather

15 Review, 139(3):976-991, 2011.

16 [107] R. SIMPSON. Liquid water in squall lines and hurricanes at air temperatures

17 lower than-40 deg c(jet aircraft icing in convective clouds at air temperatures lower

18 than minus 60 degrees c). 1963., 1963. 
1 [108] R. W. Spencer, H. M. Goodman, and R. E. Hood. Precipitation retrieval over

2 land and ocean with the ssm/i: Identification and characteristics of the scattering

3 signal. Journal of Atmospheric and Oceanic Technology, 6(2):254-273, 1989.

4 [109] M. Steiner, R. A. Houze Jr, and S. E. Yuter. Climatological characterization of

5 three-dimensional storm structure from operational radar and rain gauge data.

6 Journal of Applied Meteorology, 34(9):1978-2007, 1995.

7 [110] J. L. Stith, J. A. Haggerty, A. Heymsfield, and C. A. Grainger. Microphysical

8 characteristics of tropical updrafts in clean conditions. Journal of Applied

9 Meteorology, 43(5):779-794, 2004.

10 [111] J. Strapp, A. Korolev, T. Ratvasky, R. Potts, A. Protat, P. May, A. Ackerman, A.

11 Fridlind, P. Minnis, J. Haggerty, et al. The high ice water content study of deep

12 convective clouds: Report on science and technical plan. In Tech. Rep. DOT/FAA/TC13 14/31. 2016.

14 [112] M. Taufour, B. Vié, C. Augros, B. Boudevillain, J. Delanoë, G. Delautier, V.

15 Ducrocq, C. Lac, J.-P. Pinty, and A. Schwarzenböck. Evaluation of the two-moment

16 scheme lima based on microphysical observations from the hymex campaign.

17 Quarterly Journal of the Royal Meteorological Society, 144(714):1398-1414, 2018.

18 [113] G. Thompson, P. R. Field, R. M. Rasmussen, and W. D. Hall. Explicit forecasts of 19 winter precipitation using an improved bulk microphysics scheme. part ii: 
1 Implementation of a new snow parameterization. Monthly Weather Review, 2 136(12):5095-5115, 2008.

3 [114] G. J. Tripoli, P. J. Flatau, and W. R. Cotton. mesoscale/cloud models. clph, $4 \quad 1: 109-111,1988$.

5 Generalized microphysics scheme for use in

6 [115] F. Veersé and J.-N. Thépaut. Multiple-truncation incremental approach for

7 four-dimensional variational data assimilation. Quarterly Journal of the Royal

8 Meteorological Society, 124(550):1889-1908, 1998.

9 [116] B. Vié, J.-P. Pinty, S. Berthet, and M. Leriche. Lima (v1. 0): A quasi two-moment

10 microphysical scheme driven by a multimodal population of cloud condensation and

11 ice freezing nuclei. Geoscientific Model Development, 9(2):567-586, 2016.

12 [117] C. J. Wall, J. R. Norris, B. Gasparini, W. L. Smith Jr, M. M. Thieman, and O.

13 Sourdeval. Observational evidence that radiative heating modifies the life cycle of

14 tropical anvil clouds. Journal of Climate, 33(20):8621-8640, 2020.

15 [118] C. Westbrook, R. Ball, P. Field, and A. Heymsfield. Theory of growth by

16 differential sedimentation, with application to snowflake formation. 2004.

17 [119] W. Wu and G. M. McFarquhar. On the impacts of different definitions of 18 maximum dimension for nonspherical particles recorded by $2 \mathrm{~d}$ imaging probes. 
1 Journal of Atmospheric and Oceanic Technology, 33(5):1057-1072, 2016.

2 [120] K.-M. Xu. Partitioning mass, heat, and moisture budgets of explicitly simulated

3 cumulus ensembles into convective and stratiform components. Journal of the

4 atmospheric sciences, 52(5):551-573, 1995.

5 [121] C. R. Yost, K. M. Bedka, P. Minnis, L. Nguyen, J. W. Strapp, R. Palikonda, K.

6 Khlopenkov, D. Spangenberg, W. L. Smith Jr, A. Protat, et al. A prototype method for

7 diagnosing high ice water content probability using satellite imager data.

8 Atmospheric measurement techniques, 11(3):1615-1637, 2018.

9 [122] C. L. Ziegler. Retrieval of thermal and microphysical variables in observed

10 convective storms. Part 1: Model development and preliminary testing. Journal of

11 the atmospheric sciences, 42(14):1487-1509, 1985.

12 [123] E. Zipser. Mesoscale and convective-scale downdrafts as distinct components

13 of squall-line structure. Monthly Weather Review, 105(12):1568-1589, 1977. 


\section{Tables:}

8

\begin{tabular}{|c|c|c|c|c|c|}
\hline & Graupel & Pristine ice (plates) & Snow & Rain & Liquid cloud water \\
\hline $\mathbf{a}$ & 19,6 & 0,82 & 0,02 & 524 & 524 \\
\hline b & 2.8 & 2.5 & 1.9 & 3 & 3 \\
\hline c & 124 & 800 & 5.1 & 842 & $3.2 \times 10^{7}$ \\
\hline d & 0.66 & 1 & 0.27 & 0.8 & 2 \\
\hline$\alpha$ & 1 & 3 & 1 & 1 & 3 (ocean) \\
\hline
\end{tabular}




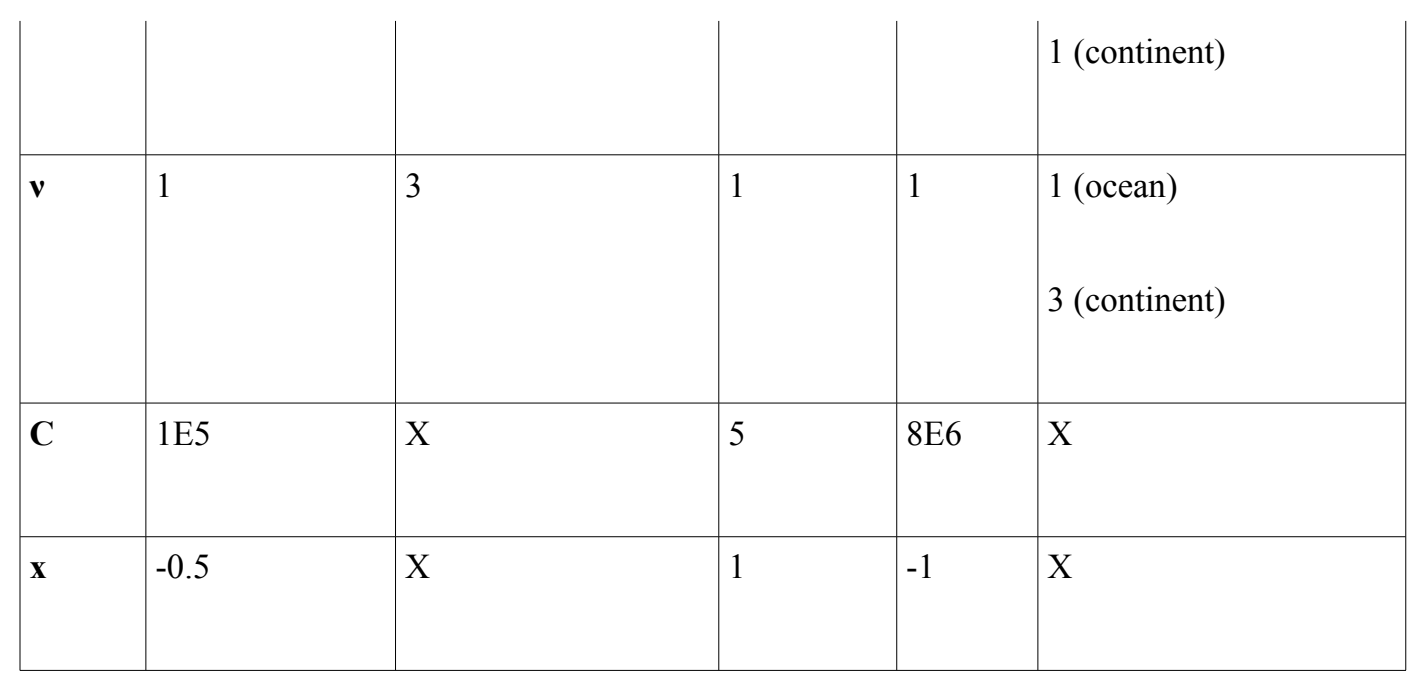

1 Table I - Coefficient values (S.I. unit), describing the ICE-3 ice species

2

\begin{tabular}{|c|c|c|c|}
\hline & Convective & Stratiform & Cirriform \\
\hline Number of segments & 103 & 241 & 226 \\
\hline
\end{tabular}

3

Table II - Distribution of observations regarding the MCS sub-regions.

4

\begin{tabular}{|c|c|c|c|c|}
\hline & $(\boldsymbol{\alpha} ; \boldsymbol{v})$ & $\boldsymbol{v}$ for $\boldsymbol{\alpha}=\mathbf{1}$ & $\boldsymbol{v}$ for $\boldsymbol{\alpha}=\mathbf{0 , 5}$ & $\boldsymbol{v}$ for $\boldsymbol{\alpha}=\mathbf{0 , 2 5}$ \\
\hline All PSDs & $(0.214 ; 43.7)$ & 1.3 & 7.54 & 38.2 \\
\hline $\mathbf{- 1 0}^{\circ} \mathbf{C}$ & $(0.163 ; 75)$ & 1.14 & 7.54 & 33.3 \\
\hline $\mathbf{- 3 0}^{\circ} \mathbf{C}$ & $(0.25 ; 38.2)$ & 1.49 & 9.88 & 38.2 \\
\hline
\end{tabular}




\begin{tabular}{|l|l|l|l|l|}
$-\mathbf{4 5}^{\circ} \mathbf{C}$ & $(0.247 ; 43.7)$ & 1.95 & 11.3 & 50 \\
\hline
\end{tabular}

1 Table III - Best $(\alpha, v)$ pairs for all PSDs and at $-10^{\circ} \mathrm{C},-30^{\circ} \mathrm{C}$ and $-45^{\circ} \mathrm{C}$ temperatures.

2 In the last three rows, setting a constant, the best corresponding $v$ values are given for

3 each ensemble.

4

5

6

7

8

9

10

11

\section{Figures:}




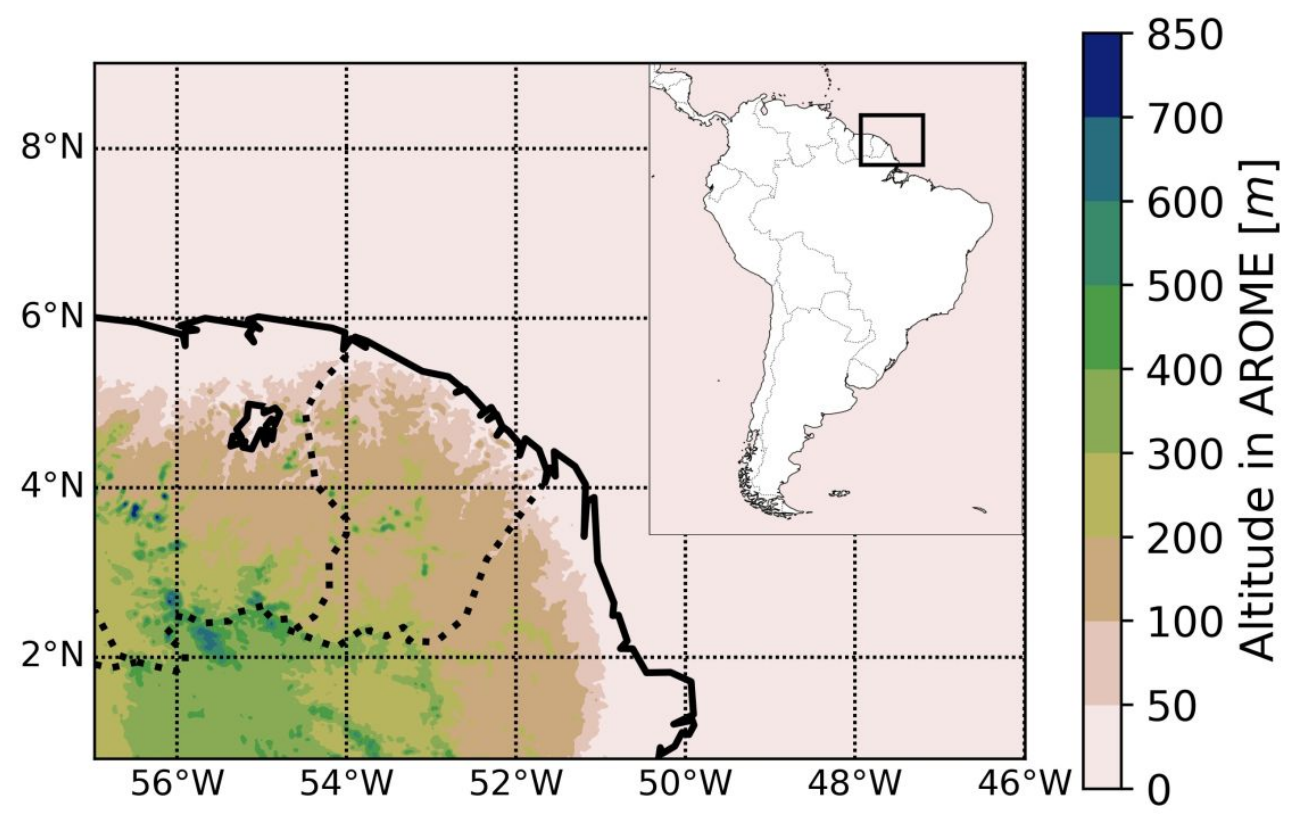

2 FIGURE 1-AROME domain over French Guiana. The color scale shows the orography. 
(a)
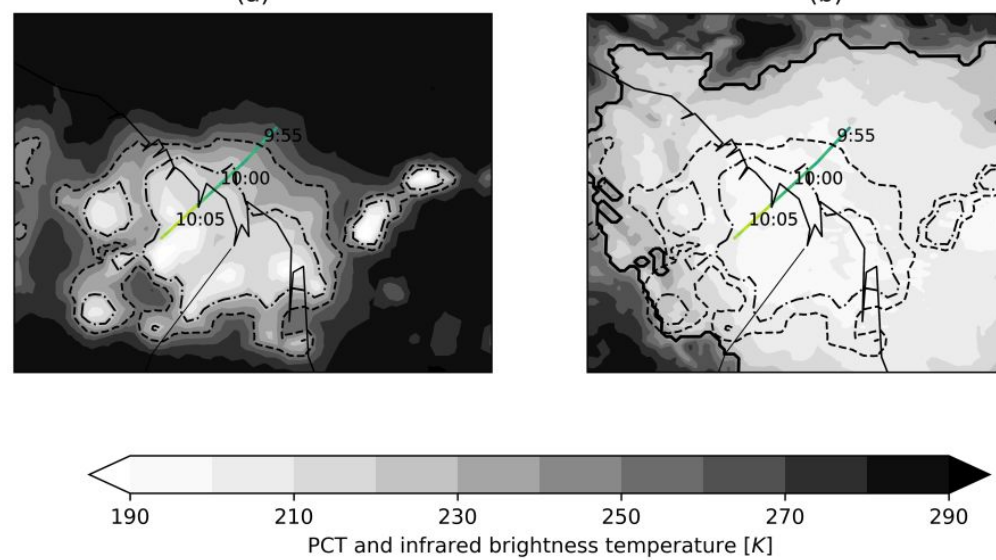

(b)
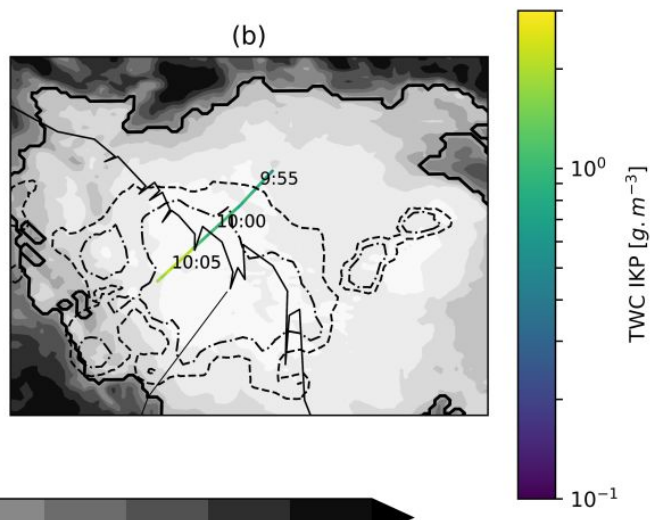

1
$\vdots$
0
0
0
$\vdots$
$\vdots$

1 FIGURE 2 - MCS sampled on May 29, 2015 around 1000 UTC by the Falcon-20 flying

2 at an elevation where air temperature is around $-30^{\circ} \mathrm{C}$. The colored line shows the TWC

3 measured by IKP2 along the flight path. The MCS is observed in the (a) microwave by

4 SSMIS at 0940UTC and (b) in the infrared by GOES-13 (b). Identified MCS regions are shown using black lines (see text for definitions).
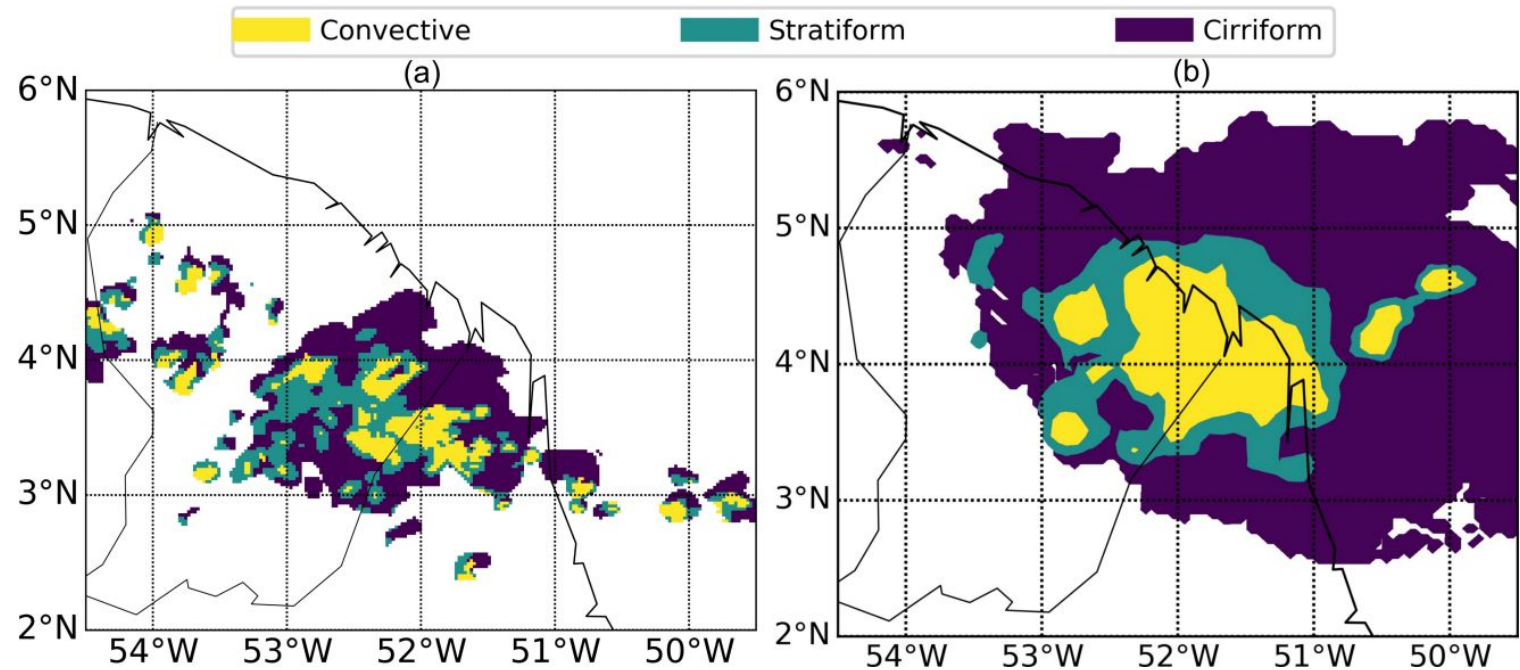
FIGURE 3 -Identification of convective/stratiform/cirriform regions of the MCS 

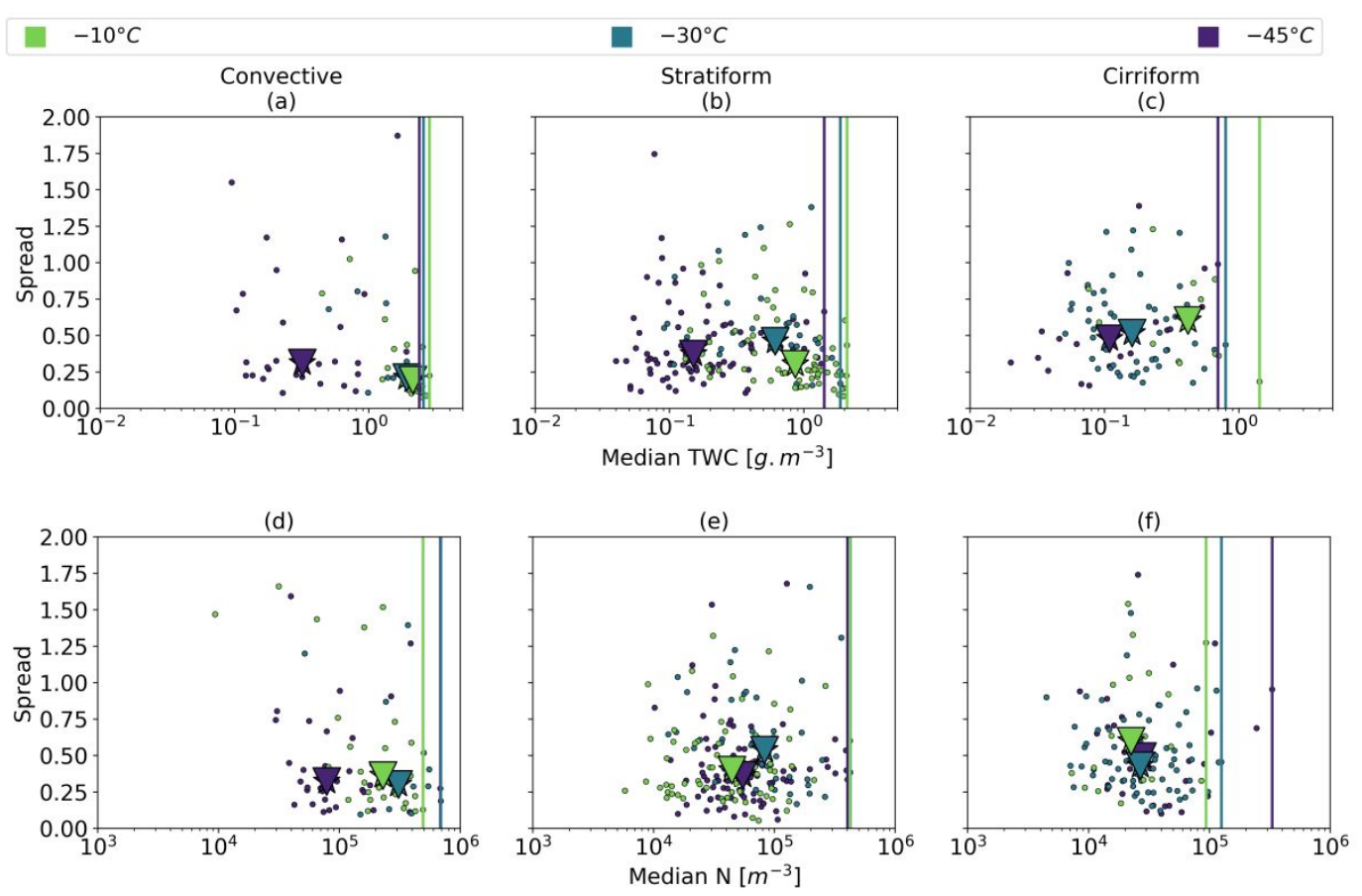

6 FIGURE 4-Spread of TWC ( $a, b$ and $c)$ and $N(d$, e and $f)$ as a function of median

$7 \quad$ values within each segment (dots) for the different MCS regions: (a, d) convective (b, e)

8 stratiform and $(c, f)$ cirriform. Colors show the segment temperature. Triangles represent

9 the median of all segments for a given temperature level. Maximum median TWC and $N$

10 for each temperature level are highlighted by a vertical bar of the corresponding color. 


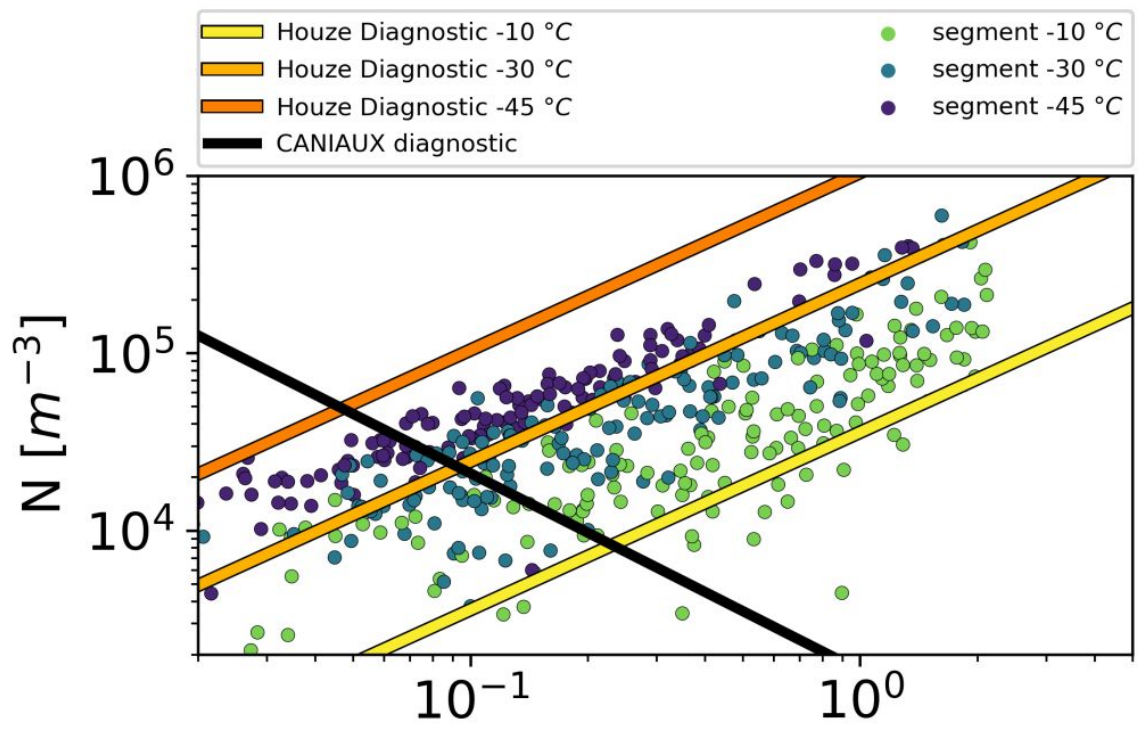

TWC $\left[g . \mathrm{m}^{-3}\right]$

1 FIGURE 5 -Median $N$ as a function of median TWC (dots) for each stratiform and

$2 \quad$ cirriform segment and temperature level are shown in colors. Colored lines show the

3 diagnostic concentration of Houze et al. (1979) in warm colors and as deduced from 


\begin{tabular}{|l|l|}
\hline Convective & Observation \\
Stratiform & AROME \\
Cirriform & \\
\hline
\end{tabular}

(a)
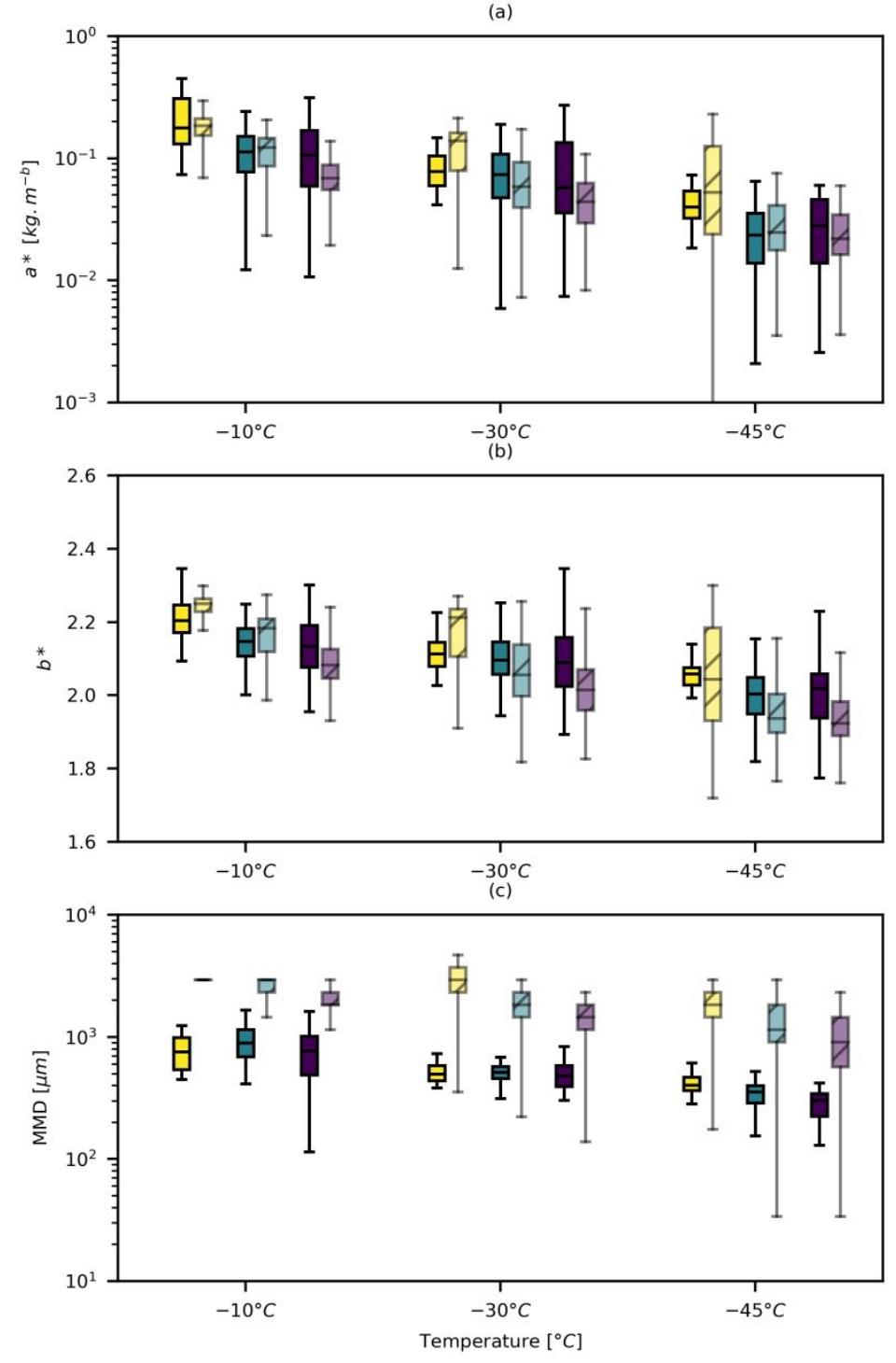

1 FIGURE 6-Box-plots of mass diameter coefficients $\left(a^{*}, b^{*}\right)$ and MMD as a function of

2 the dynamical environment partitioned by temperature. Hatched box-plots represent

$3 \quad$ observed values, while filled box-plots are for AROME outputs. 


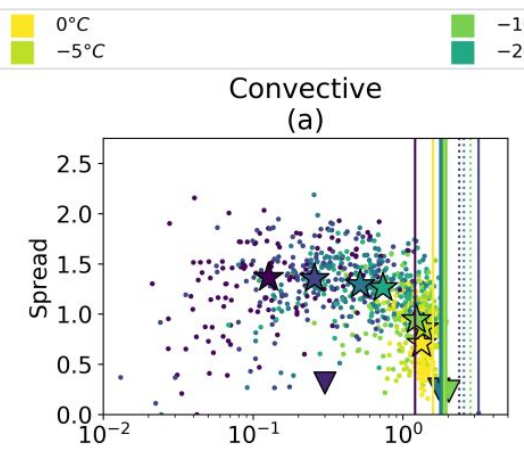

(d)

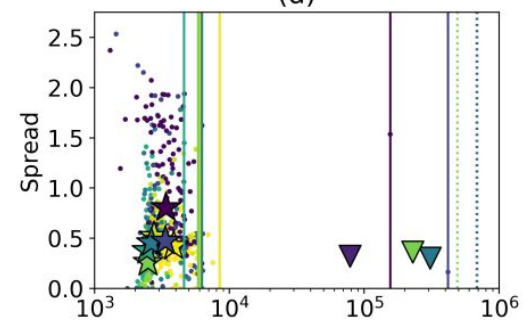

$-10^{\circ} \mathrm{C}$
$-20^{\circ} \mathrm{C}$

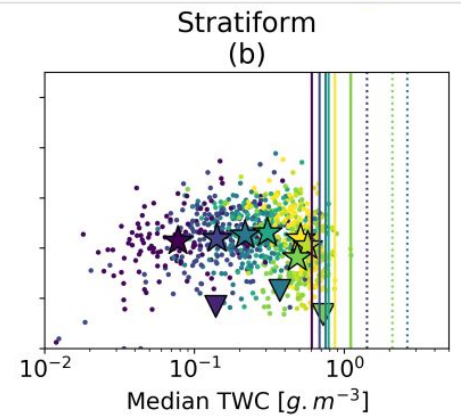

(e)

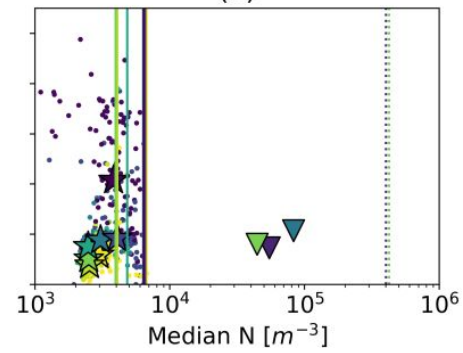

$-30^{\circ} \mathrm{C}$
$-40^{\circ} \mathrm{C}$ $40^{\circ} \mathrm{C}$

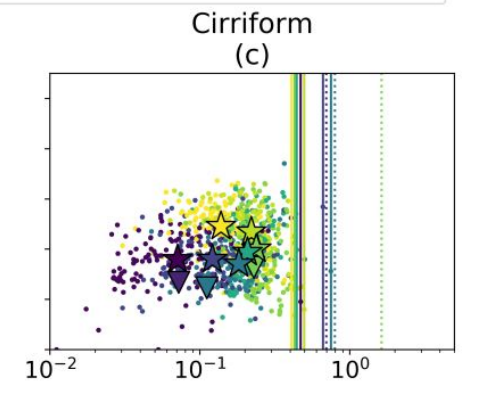

(f)

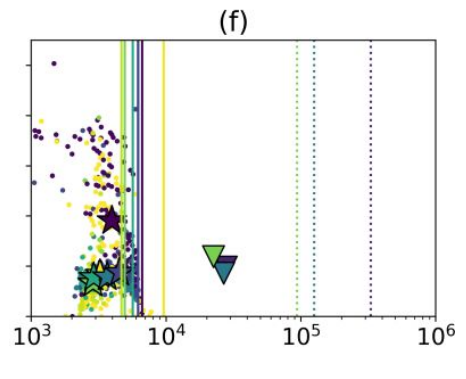

1 FIGURE 7 - As in Figure 4 but for AROME. Stars represent the simulated medians for a

2 given temperature level. Median (colored triangles) and maximum median (dotted line) 


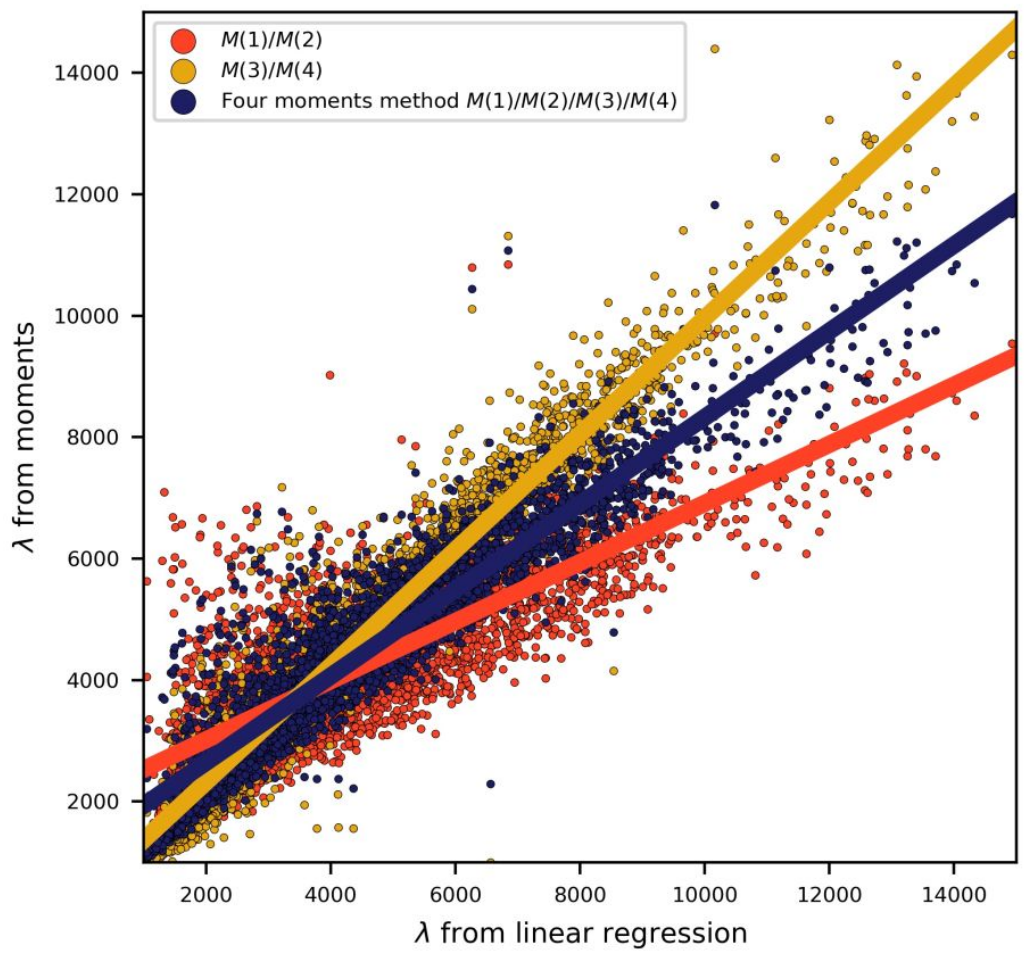

3 FIGURE 8 -Scatter plot of $\lambda$ retrieved assuming different moment combinations as a

4 function of $\lambda$ deduced from linear regressions assuming a MP distribution. Solid lines 

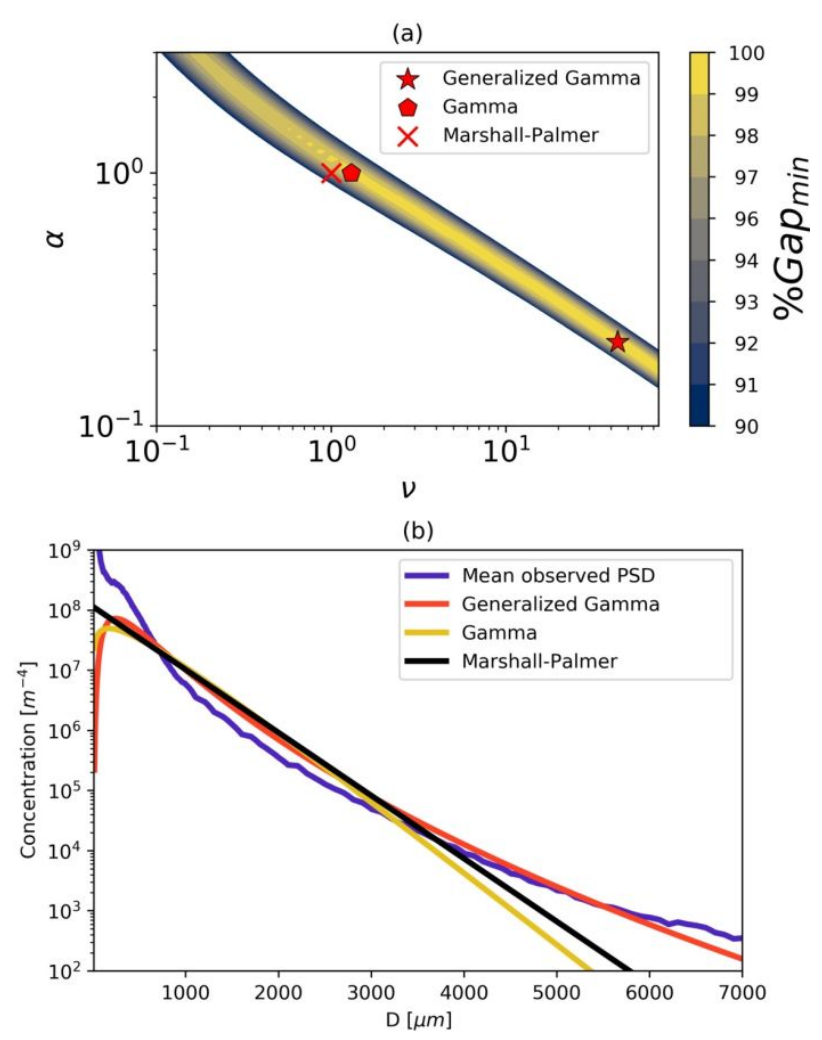

1

2 FIGURE 9-(a) Ratio of the gap minimum over the gap value for a given $\alpha$ and $v$ (in per

3 cent, color-scale). Red crosses, pentagons and stars indicate the location of the

$4 \quad$ Marshall-Palmer $(\alpha=v=1)$, the best gamma fit $(\alpha=1)$ and the best generalized gamma fit,

$5 \quad$ respectively. These shapes (respectively black, yellow and red lines) are used to fit the

$6 \quad$ mean PSD (purple line) in (b).

7

8

9 

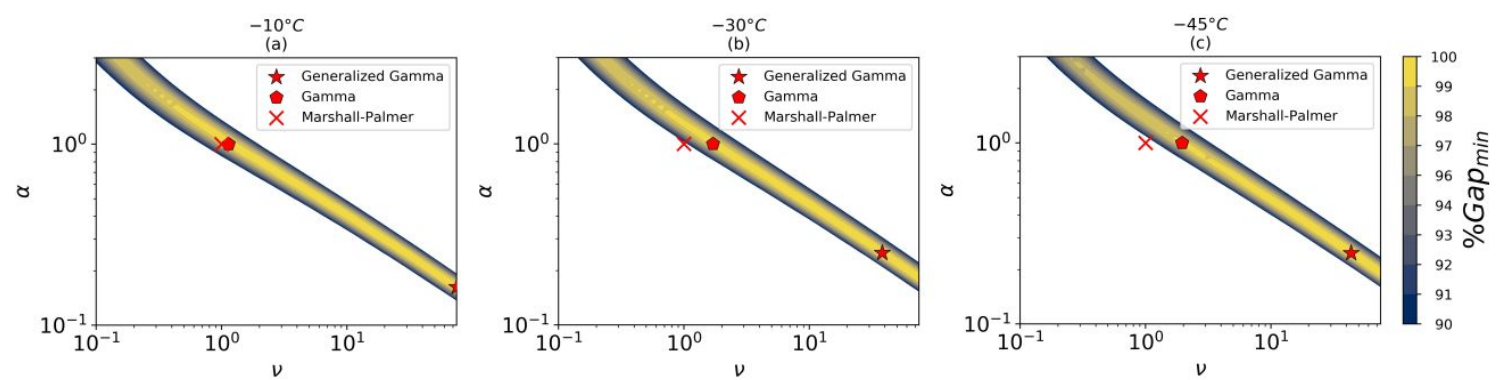

2 FIGURE 10-As in Figure 9a, but for three of the temperature levels $\left(-10^{\circ} \mathrm{C}(\mathrm{a}),-30^{\circ} \mathrm{C}\right.$

(b) and $\left.-45^{\circ} \mathrm{C}(c)\right)$

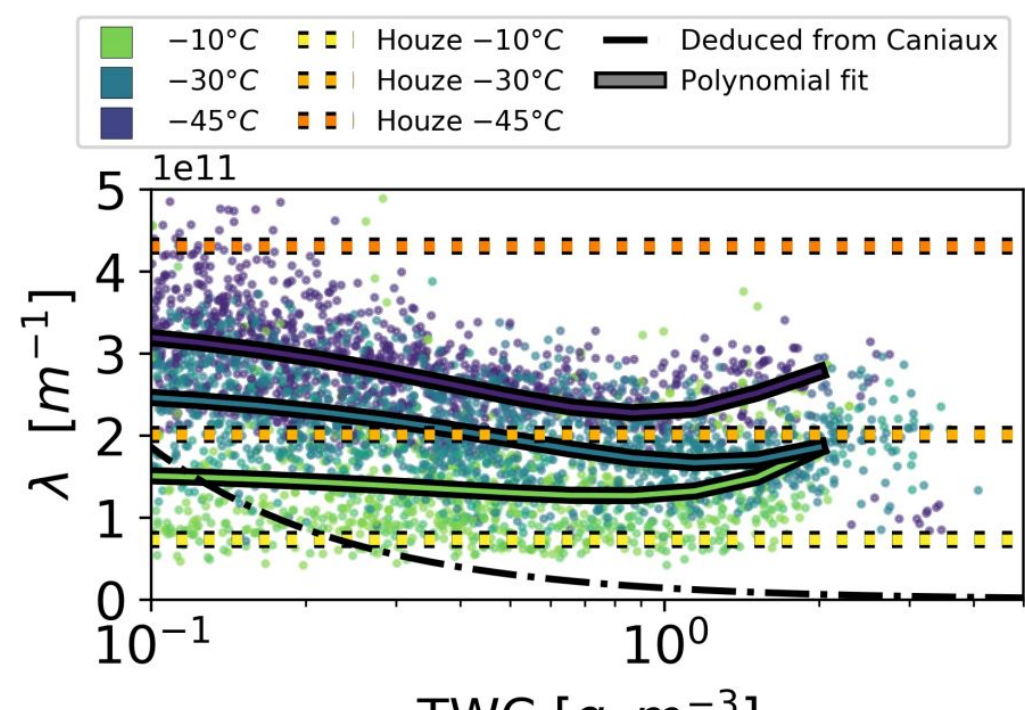

4

TWC $\left[g \cdot \mathrm{m}^{-3}\right]$

$5 \quad$ FIGURE $11-\lambda$ as a function of TWC and temperature (colors) Houze et al. (1979)

6 diagnostic is indicated by dashed lines for the three different temperature levels and the

7 Caniaux (1993) diagnostic by the dashed-dotted line. Polynomial fits are represented by 


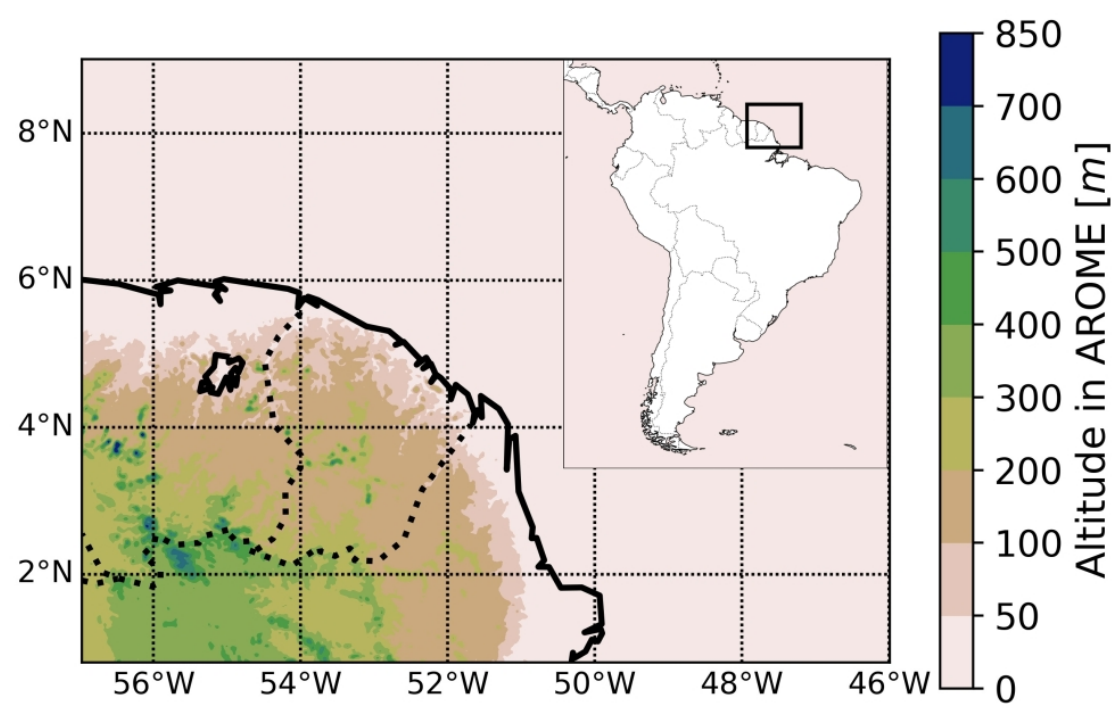

AROME domain over French Guiana. The color scale shows the orography. The dotted lines correspond to country borders. $1058 \times 705 \mathrm{~mm}(72 \times 72 \mathrm{DPI})$ 
MCS sampled on May 29, 2015 around 1000 UTC by the Falcon-20 flying at an elevation where air temperature is around $-30^{\circ} \mathrm{C}$. The colored line shows the TWC measured by IKP2 along the flight path. The MCS is observed in the (a) microwave by SSMIS at 0940UTC and (b) in the infrared by GOES-13 (b). Identified MCS regions are shown using black lines (see text for definitions). 


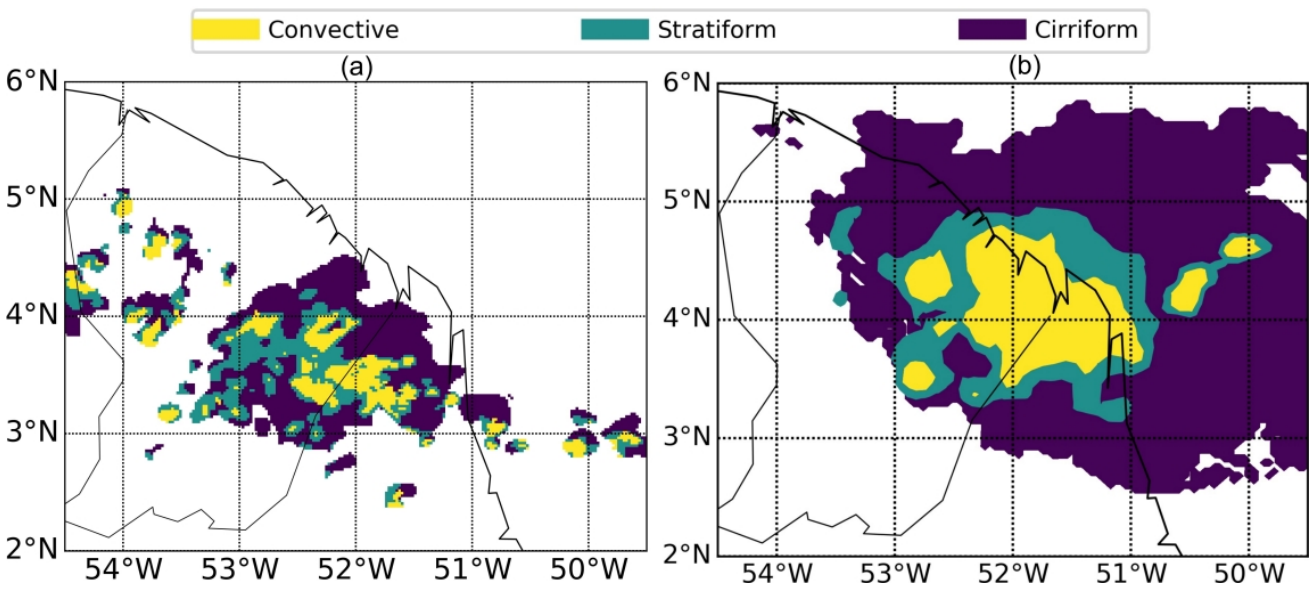

Identification of convective/stratiform/cirriform regions of the MCS sampled on May 29, 2015 at 1000 UTC (a) in AROME and (b) classified using spaceborne observations.

$1726 \times 763 \mathrm{~mm}(72 \times 72 \mathrm{DPI})$ 

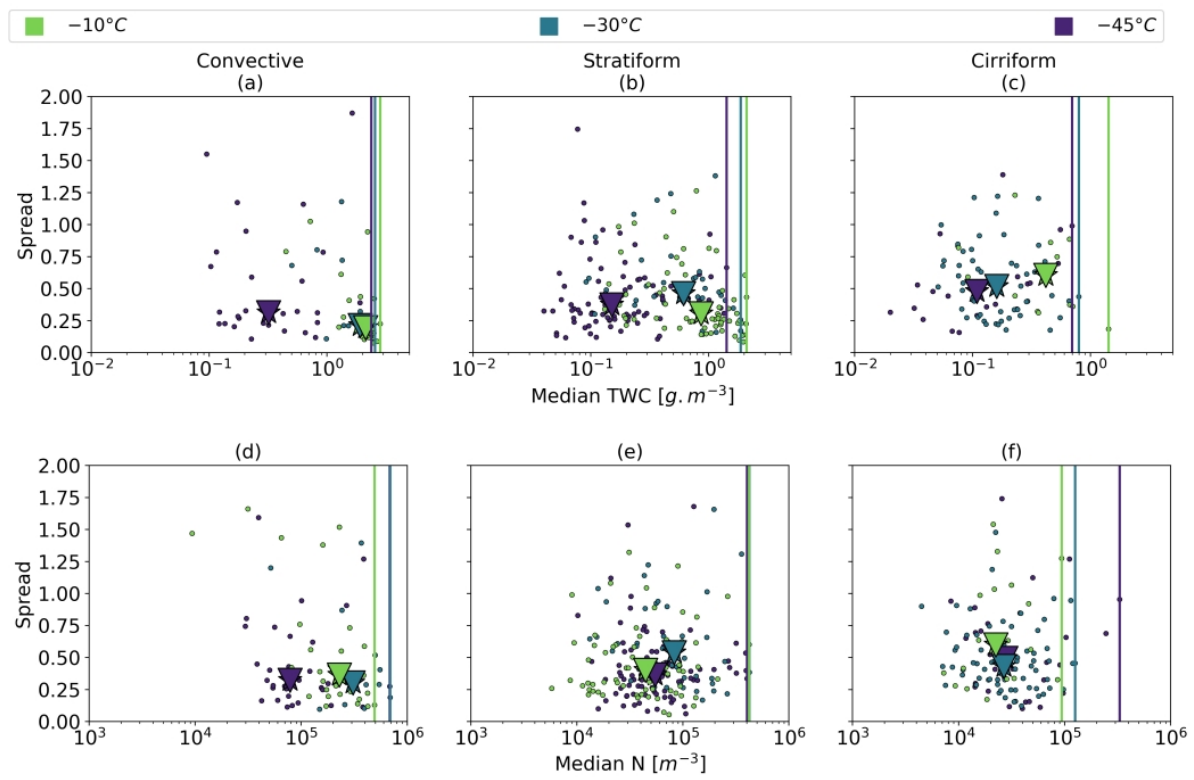

Spread of TWC ( $a, b$ and $c$ ) and N (d, e and f) as a function of median values within each segment (dots) for the different MCS regions: $(a, d)$ convective $(b, e)$ stratiform and $(c, f)$ cirriform. Colors show the segment temperature. Triangles represent the median of all segments for a given temperature level. Maximum median TWC and $\mathrm{N}$ for each temperature level are highlighted by a vertical bar of the corresponding color. 
Median $\mathrm{N}$ as a function of median TWC (dots) for each stratiform and cirriform segment and temperature level are shown in colors. Colored lines show the diagnostic concentration of Houze et al. (1979) in warm colors and as deduced from Caniaux (1993) in black. 
Box-plots of mass diameter coefficients ( $a^{*}, b^{*}$ ) and MMD as a function of the dynamical environment partitioned by temperature. Hatched box-plots represent observed values, while filled box-plots are for AROME outputs.

$101 \times 177 \mathrm{~mm}(500 \times 500 \mathrm{DPI})$ 

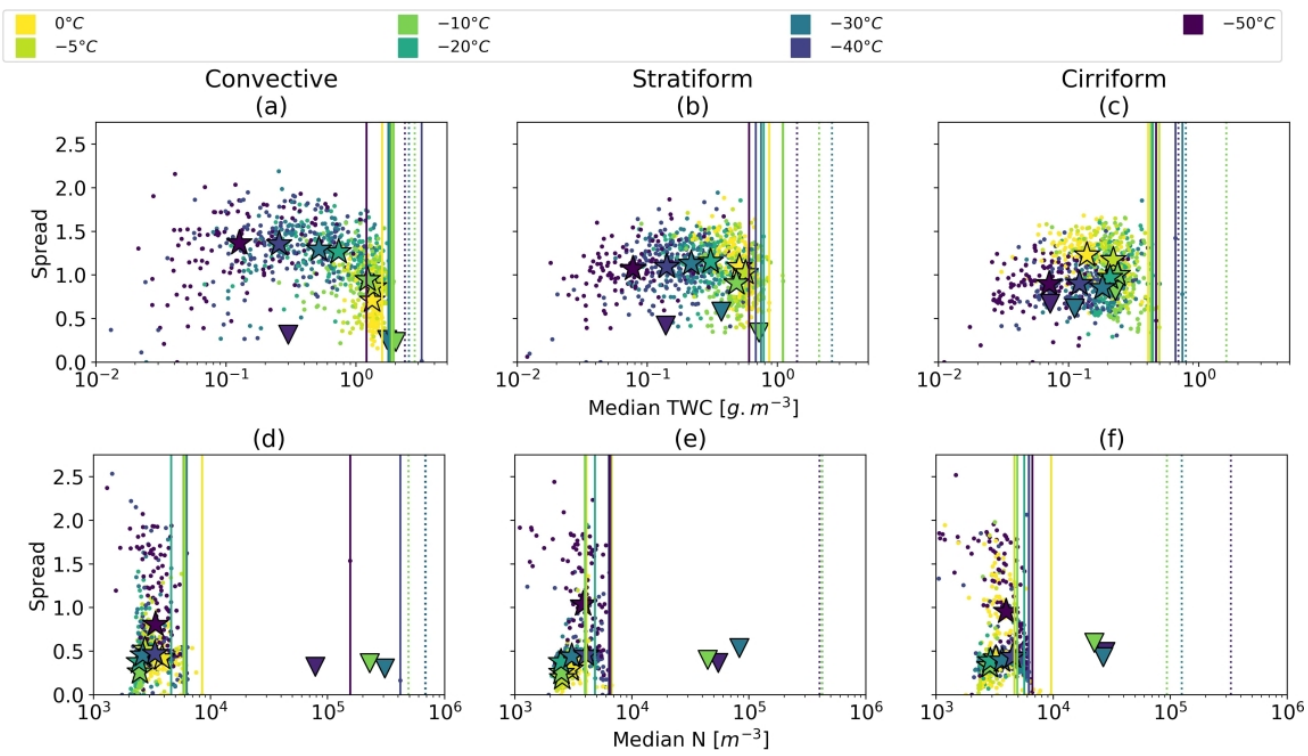

As in Figure 4 but for AROME. Stars represent the simulated medians for a given temperature level. Median (colored triangles) and maximum median (dotted line) are the observed values from Figure 4. 


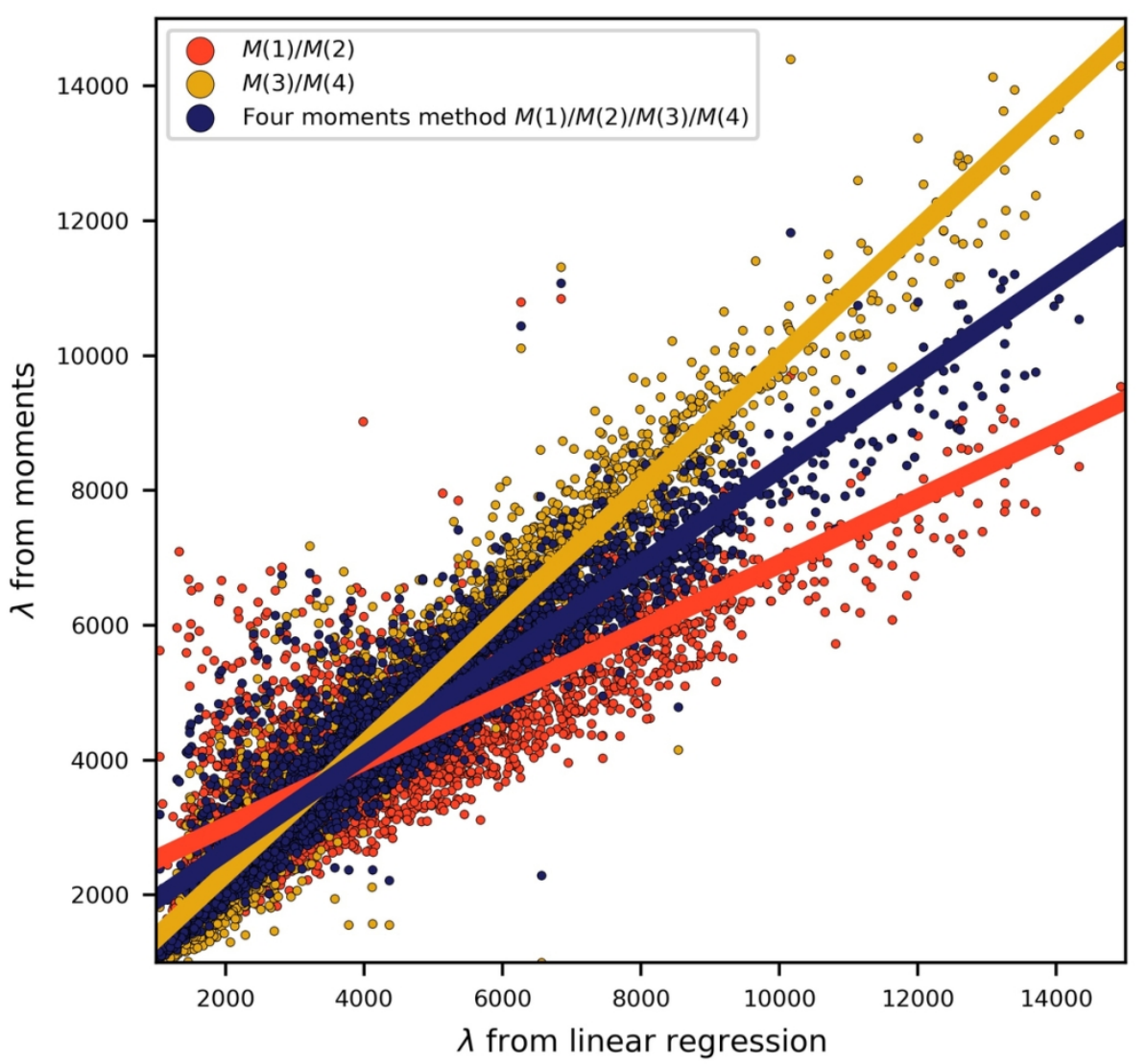

Scatter plot of $\lambda$ retrieved assuming different moment combinations as a function of $\lambda$ deduced from linear regressions assuming a MP distribution. Solid lines correspond to the linear regression performed for each moment combinations.

$$
114 \times 114 \mathrm{~mm} \text { ( } 300 \times 300 \text { DPI) }
$$


(a) Ratio of the gap minimum over the gap value for a given a and $v$ (in per cent, color-scale) . Red crosses, pentagons and stars indicate the location of the Marshall-Palmer $(a=v=1)$, the best gamma fit $(a=1)$ and the best generalized gamma fit, respectively. These shapes (respectively black, yellow and red lines) are used to fit the mean PSD (purple line) in (b). 

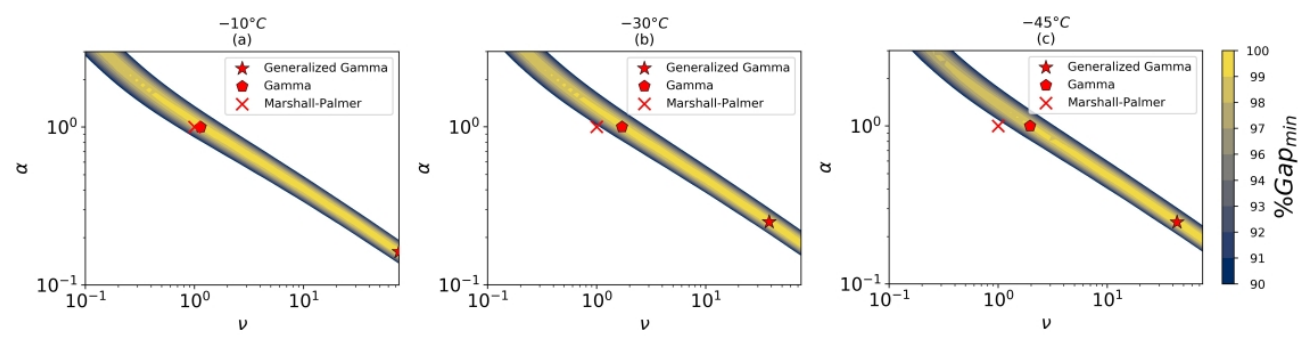

As in Figure $9 \mathrm{a}$, but for three of the temperature levels $\left(-10^{\circ} \mathrm{C}(\mathrm{a}),-30^{\circ} \mathrm{C}(\mathrm{b})\right.$ and $\left.-45^{\circ} \mathrm{C}(\mathrm{c})\right)$

$379 \times 102 \mathrm{~mm}$ ( $400 \times 400$ DPI) 
$\lambda$ as a function of TWC and temperature (colors) Houze et al. (1979) diagnostic is indicated by dashed lines for the three different temperature levels and the Caniaux (1993) diagnostic by the dashed -dotted line. Polynomial fits are represented by filled lines. 


\begin{tabular}{|c|c|c|c|c|c|}
\hline & Graupel & Pristine ice (plates) & Snow & Rain & Liquid cloud water \\
\hline $\mathbf{a}$ & 19,6 & 0,82 & 0,02 & 524 & 524 \\
\hline b & 2.8 & 2.5 & 1.9 & 3 & 3 \\
\hline c & 124 & 800 & 5.1 & 842 & $3.2 \times 10^{7}$ \\
\hline d & 0.66 & 1 & 0.27 & 0.8 & 2 \\
\hline$\alpha$ & 1 & 3 & 1 & 1 & $\begin{array}{l}3 \text { (ocean) } \\
1 \text { (continent) }\end{array}$ \\
\hline$v$ & 1 & 3 & 1 & 1 & $\begin{array}{l}1 \text { (ocean) } \\
3 \text { (continent) }\end{array}$ \\
\hline C & $1 \mathrm{E} 5$ & $\mathrm{X}$ & 5 & $8 \mathrm{E} 6$ & $\mathrm{X}$ \\
\hline $\mathbf{x}$ & -0.5 & $X$ & 1 & -1 & $\mathrm{X}$ \\
\hline
\end{tabular}

$\underline{\text { Table I - Coefficient values (S.I. unit), describing the ICE-3 ice species }}$ 


\begin{tabular}{|l|c|c|c|}
\hline & Convective & Stratiform & Cirriform \\
\hline Number of segments & 103 & 241 & 226 \\
\hline
\end{tabular}

Table II - Distribution of observations regarding the MCS sub-regions. 


\begin{tabular}{|c|c|c|c|c|}
\hline & $(\boldsymbol{\alpha} ; \boldsymbol{v )}$ & $\boldsymbol{v}$ for $\boldsymbol{\alpha}=\mathbf{1}$ & $\boldsymbol{v}$ for $\boldsymbol{\alpha}=\mathbf{0 , 5}$ & $\mathbf{v}$ for $\boldsymbol{\alpha}=\mathbf{0 , 2 5}$ \\
\hline All PSDs & $(0.214 ; 43.7)$ & 1.3 & 7.54 & 38.2 \\
\hline $\mathbf{- 1 0}^{\circ} \mathbf{C}$ & $(0.163 ; 75)$ & 1.14 & 7.54 & 33.3 \\
\hline $\mathbf{- 3 0}^{\circ} \mathbf{C}$ & $(0.25 ; 38.2)$ & 1.49 & 9.88 & 38.2 \\
\hline$-\mathbf{4 5}^{\circ} \mathbf{C}$ & $(0.247 ; 43.7)$ & 1.95 & 11.3 & 50 \\
\hline
\end{tabular}

$\underline{\text { Table III - Best }(\alpha, v) \text { pairs for all PSDs and at }-10^{\circ} \mathrm{C},-30^{\circ} \mathrm{C} \text { and }-45^{\circ} \mathrm{C} \text { temperatures. In the last }}$ three rows, setting $\alpha$ constant, the best corresponding $v$ values are given for each ensemble. 


\section{Dynamic-wise evaluation of the microphysics of the}

\section{AROME model in the context of ice crystal icing using in- situ data of the HAIC 2015 field campaign}

Jean Wurtz*, Dominique Bouniol, Benoît Vié, Christine Lac

CNRM, Université de Toulouse, Météo-France, CNRS, Toulouse, France

Correspondence : Jean Wurtz, CNRM - Météo-France, 42 avenue Gaspard Coriolis, 31057

Toulouse, France.

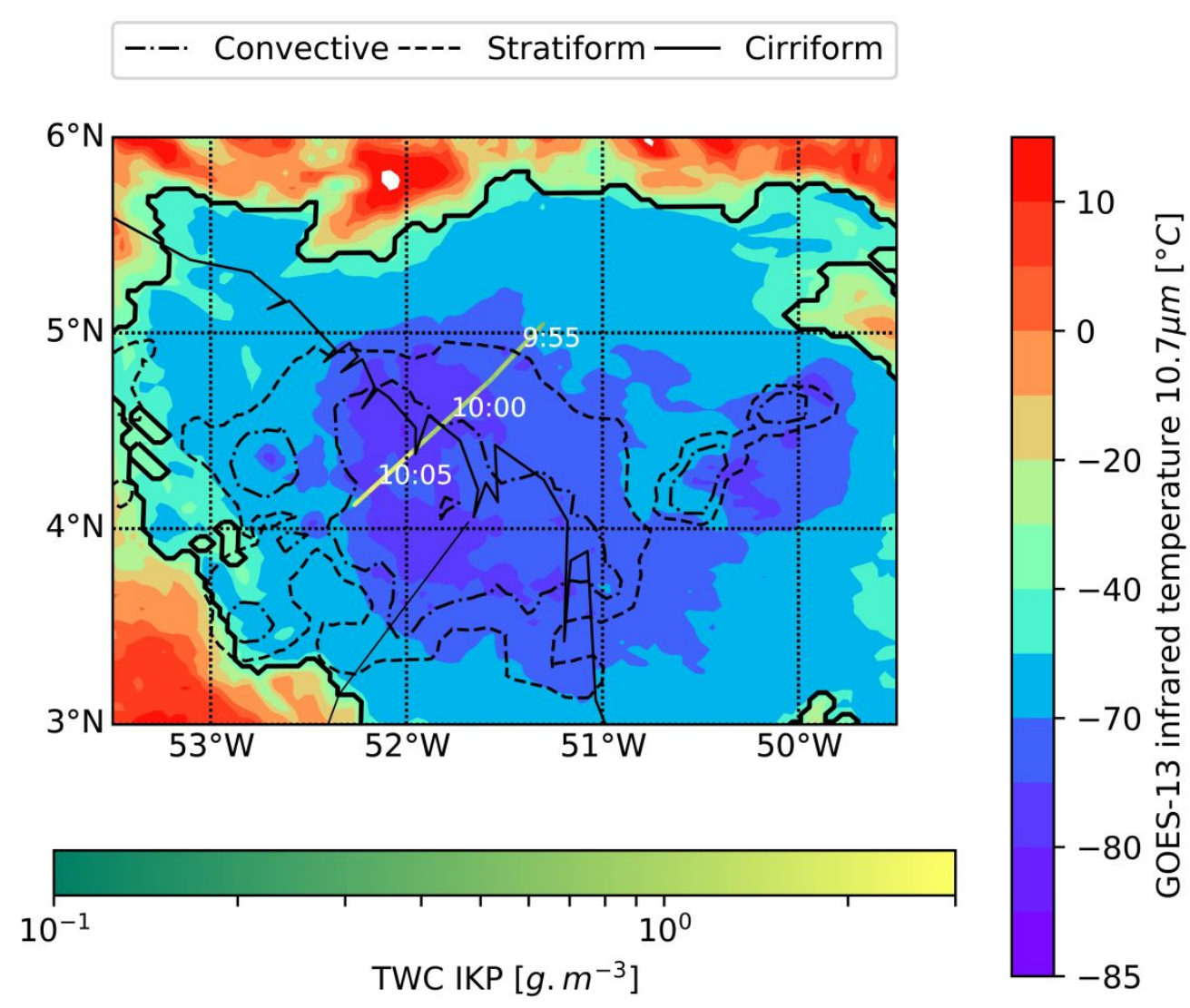

email : jean.wurtz@meteo.fr 
In some deep tropical convective clouds, Ice Crystal Icing is an unavoidable threat for aeronautics. The possibility to forecast such event with the french meso-scale model AROME is investigated in this article thanks to the HAIC 2015 field campaign and a contextualization of the deep convective clouds into convective, stratiform and cirriform parts. Guidelines including modifications on the snow particle size distribution and snow concentration diagnostic are given to improve the skills of microphysical schemes. 